OPEN ACCESS

Edited by:

Michael R. Gold

University of British Columbia, Canada

Reviewed by:

Rodney P. DeKoter,

University of Western Ontario, Canada

Wenxia Song,

University of Maryland, College Park,

United States

${ }^{*}$ Correspondence:

Pieta K. Mattila

pieta.mattila@utu.fi

Specialty section:

This article was submitted to

B Cell Biology,

a section of the journal

Frontiers in Immunology

Received: 18 November 2019

Accepted: 16 March 2020

Published: 16 April 2020

Citation:

Sarapulov AV, Petrov $P$ Hernández-Pérez S, Šuštar $V$, Kuokkanen E, Cords L, Samuel RVM, Vainio M, Fritzsche M, Carrasco YR and Mattila PK (2020) Missing-in-Metastasis/Metastasis

Suppressor 1 Regulates B Cell Receptor Signaling, B Cell Metabolic Potential, and T Cell-Independent

Immune Responses.

Front. Immunol. 11:599.

doi: 10.3389/fimmu.2020.00599

\section{Missing-in-Metastasis/Metastasis Suppressor 1 Regulates B Cell Receptor Signaling, B Cell Metabolic Potential, and T Cell-Independent Immune Responses}

\author{
Alexey V. Sarapulov ${ }^{1,2}$, Petar Petrov ${ }^{1,2}$, Sara Hernández-Pérez ${ }^{1,2}$, Vid Šuštar ${ }^{1}$, \\ Elina Kuokkanen ${ }^{1}$, Lena Cords ${ }^{3}$, Rufus V. M. Samuel ${ }^{1}$, Marika Vainio ${ }^{1,2}$, Marco Fritzsche ${ }^{4,5}$, \\ Yolanda R. Carrasco ${ }^{6}$ and Pieta K. Mattila ${ }^{1,2 *}$ \\ ${ }^{1}$ Institute of Biomedicine and MediCity Research Laboratories, University of Turku, Turku, Finland, ${ }^{2}$ Turku Bioscience, \\ University of Turku and Åbo Akademi University, Turku, Finland, ${ }^{3}$ MRC Human Immunology Unit, Weatherall Institute of \\ Molecular Medicine, University of Oxford, Oxford, United Kingdom, ${ }^{4}$ Kennedy Institute for Rheumatology, University of \\ Oxford, Oxford, United Kingdom, ${ }^{5}$ Rosalind Franklin Institute, Didcot, United Kingdom, ${ }^{6}$ Department of Immunology and \\ Oncology, Centro Nacional de Biotecnología (CNB)-CSIC, Madrid, Spain
}

Efficient generation of antibodies by $\mathrm{B}$ cells is one of the prerequisites of protective immunity. B cell activation by cognate antigens via B cell receptors (BCRs), or pathogen-associated molecules through pattern-recognition receptors, such as Toll-like receptors (TLRs), leads to transcriptional and metabolic changes that ultimately transform B cells into antibody-producing plasma cells or memory cells. BCR signaling and a number of steps downstream of it rely on coordinated action of cellular membranes and the actin cytoskeleton, tightly controlled by concerted action of multiple regulatory proteins, some of them exclusive to B cells. Here, we dissect the role of Missing-In-Metastasis (MIM), or Metastasis suppressor 1 (MTSS1), a cancer-associated membrane and actin cytoskeleton regulating protein, in B cell-mediated immunity by taking advantage of MIM knockout mouse strain. We show undisturbed B cell development and largely normal composition of B cell compartments in the periphery. Interestingly, we found that $\mathrm{MIM}^{-/-} \mathrm{B}$ cells are defected in BCR signaling in response to surface-bound antigens but, on the other hand, show increased metabolic activity after stimulation with LPS or CpG. In vivo, MIM knockout animals exhibit impaired IgM antibody responses to immunization with $T$ cell-independent antigen. This study provides the first comprehensive characterization of MIM in B cells, demonstrates its regulatory role for B cell-mediated immunity, as well as proposes new functions for MIM in tuning receptor signaling and cellular metabolism, processes, which may also contribute to the poorly understood functions of MIM in cancer.

Keywords: MIM, MTSS1, I-BAR domain protein, BCR, B cell receptor signaling, actin cytoskeleton, TLR, metabolism 


\section{INTRODUCTION}

Adaptive immune responses, such as efficient clearing of pathogens while maintaining the homeostasis of the host, depend on fine-tuned balance of various signals. Increasing evidence points toward an important role of the actin cytoskeleton and plasma membrane organization at the crossroads of various signaling pathways orchestrating lymphocyte action (1). In B cells, the actin cytoskeleton enables changes in cell morphology, required, for instance, during the formation of the immunological synapse (2). Interestingly, actin cytoskeleton and plasma membrane also potently regulate $\mathrm{B}$ cell receptor (BCR) signaling $(1,3,4)$. A plethora of cytoskeletal regulator proteins enable the multifaceted roles of the actin cytoskeleton in living cells. Lymphocytes generally present very characteristic protein expression patterns and considering the specialized functions of these immune cells, it is not surprising that this also holds true for the regulators of the actin cytoskeleton. One best-known example of such protein is Wiscott-Aldrich syndrome (WAS) protein (WASp), a critical regulator of lymphocyte function and an activator of Arp2/3 actin filament (F-actin) nucleator complex (5).

A highly conserved, cancer-associated protein linked to the regulation of both the actin cytoskeleton and the plasma membrane, Missing in Metastasis (MIM) or Metastasis Suppressor 1 (MTSS1), is highly expressed in spleen and particularly in B cells (6) (BioGPS.org and ImmGen.org portals). MIM belongs to a family of proteins with a characteristic inverse Bin, Amphiphysin, Rvs (I-BAR) domain, also known as IRSp53 and MIM homology domain (IMD), which binds and deforms cellular membranes $(7,8)$. It also directly interacts with and regulates actin via its C-terminal WASp homology 2 (WH2) domain $(6,9)$ and indirectly via interactions with other actin regulatory proteins, such as cortactin and Rac1 GTPase $(6,7,10,11)$. MIM has also been shown to regulate bone marrow and lymphoid cell trafficking presumably through regulation of CXCR4 internalization as seen in cancer cell lines (12-15). Importantly, MIM has been linked to various cancers, either as a putative tumor metastasis suppressor or promoter (16). Genetic alterations in MIM/MTSS1 gene were found in $6 \%$ of sequenced cancer samples and, depending on the cancer type, both diminished or increased gene expression profiles are seen (17). Regarding hematopoietic malignancies, MIM is upregulated, for example, in hairy cell and mantle cell lymphomas as well as in chronic lymphocytic leukemia (CLL). In CLL, interestingly, the good prognosis samples exhibit highest levels of MIM while the poor prognosis samples show lower MIM levels in comparison to good prognosis samples (17). In mice, it has been reported that upon aging, MIM knockout animals develop lymphomas resembling diffuse large B cell lymphoma (DLBCL) (12). Moreover, a degenerative kidney disease, potentially linked to impaired cell-cell junction formation, as well as a defected dendritic spine formation and neuronal alterations have been reported in MIM knockout mice $(18,19)$. These findings illustrate the complexity of MIM function, the basis of which remains enigmatic due to the lack of understanding about the molecular mechanisms and connected pathways. Despite the reported high expression in B cells and the association with hematopoietic malignancies, nothing is known about the role of MIM in activation of adaptive immune responses.

In this study, we took advantage of a MIM knockout mouse model $\left(\mathrm{MIM}^{-/-}\right.$, MIM-KO) (18) to explore the physiological role of MIM in B cell compartment, specifically in early B cell activation and mounting of the antibody responses. While we found no defects in B cell development, MIM-deficiency caused a variety of changes in mature B cells. $\mathrm{MIM}^{-/-} \mathrm{B}$ cells showed significantly reduced signaling upon stimulation with surface-bound antigens mimicking activation via immunological synapse. T cell-independent IgM responses were reduced in $\mathrm{MIM}^{-/-}$mice, while on the other hand, $\mathrm{T}$ cell-dependent immune responses appeared normal. Unlike BCR stimulation, $\mathrm{MIM}^{-/-} \mathrm{B}$ cells were robustly activated by TLR agonists that, interestingly, also led to increased metabolic activity in cells lacking MIM. Our study highlights the complex role of MIM in different cellular functions and can serve as a stepping stone for unveiling the role of MIM in hematopoietic cancers.

\section{MATERIALS AND METHODS}

\section{Antibodies and Chemicals}

List of antibodies and reagents used in the study can be found in Table 1.

\section{Mice}

MIM knockout mouse colony was a kind gift from Prof. Pekka Lappalainen and Dr. Pirta Hotulainen from the University of Helsinki and Minerva Foundation Institute for Medical Research (18). The strain, in $\mathrm{C} 57 \mathrm{Bl} / 6$ background, had no apparent health problems until the age of 8 months when mice were last sacrificed; however, we observed that from all genotyped animals that were kept alive, 18 pups developed hydrocephaly over the study period. Among them, 17 were knockout, 1 heterozygote, and 0 wild type. To generate this strain, Saarikangas et al. (18) introduced a Neo-cassette, containing several stop codons, by homologous recombination into Exon 1 of $M I M / M t s s 1$ gene in 129/Sv ES-cells. Chimeric mice were backcrossed to C57Bl/6J background for several generations and the colony in Turku was established by breedings of heterozygote founder animals. All experiments were done with age- and sex-matched animals and WT littermate controls were used whenever possible.

\section{Immunizations}

At the age of 3-4 months, groups of WT and $M I M^{-/-}$ females were immunized with $\mathrm{NP}_{40}$-FICOLL (F-1420, Biosearch Technologies) for T-independent (TI) immunization or $\mathrm{NP}_{31}$ KLH (N-5060, Biosearch Technologies) for T-dependent (TD) immunization. Each mouse received $50 \mu \mathrm{g}$ of antigen in $150 \mu \mathrm{l}$ of PBS ( $\mathrm{NP}_{40}$-FICOLL) or PBS/Alum (77161, Thermo Fisher) adjuvant (2:1 ratio) $\left(\mathrm{NP}_{31}-\mathrm{KLH}\right)$ solution by intraperitoneal injection. Blood $(\sim 100 \mu \mathrm{l})$ was sampled from lateral saphenous veins on day -1 (preimmunization) and every week after immunization on days $+7,+14,+21$, and +28 for both FICOLL and KLH cohorts. Secondary immunization of KLH cohort was performed on day $+135(0)$ and blood was sampled on days +134 
TABLE 1 | Key reagents table.

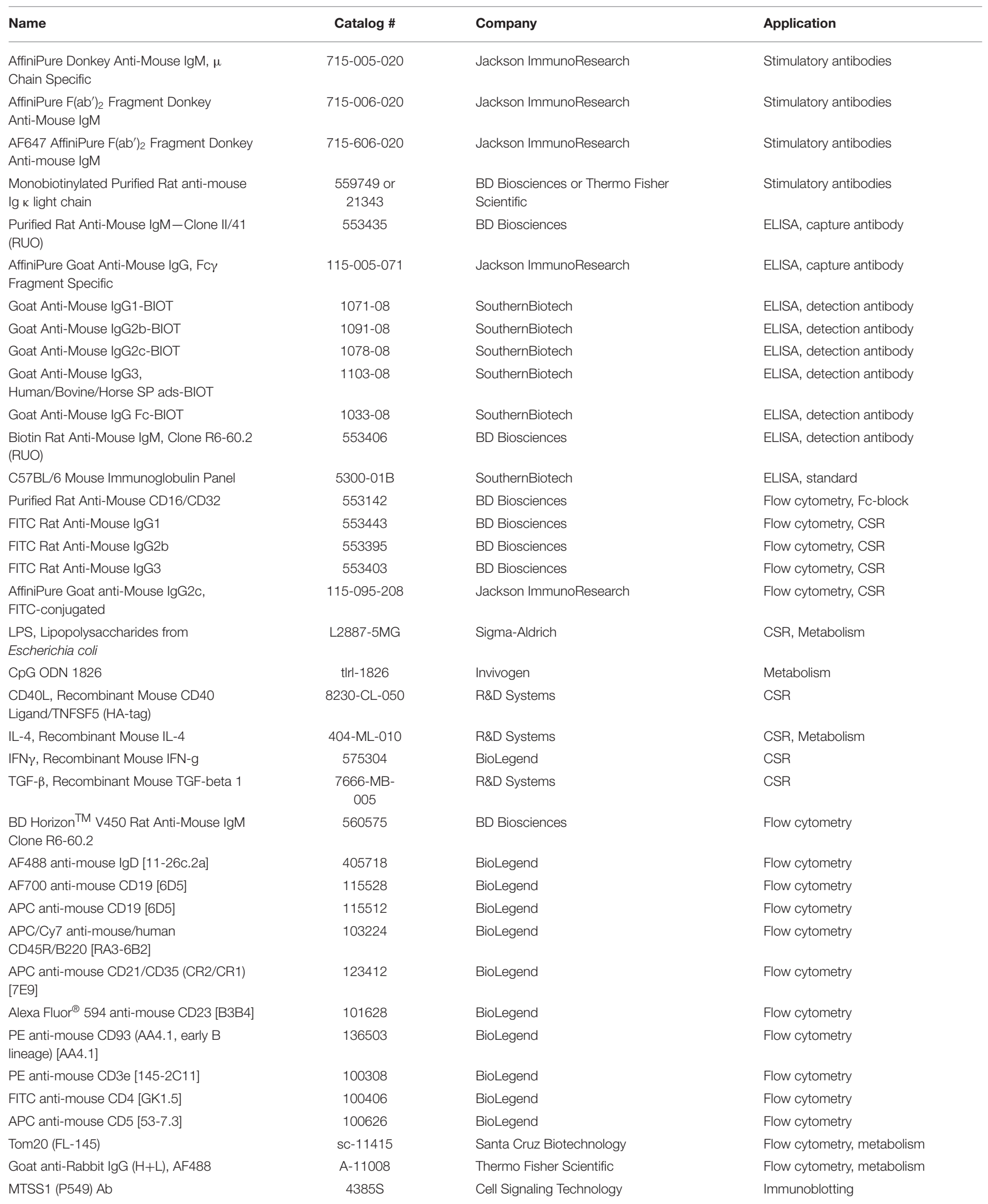


TABLE 1 | Continued

\begin{tabular}{|c|c|c|c|}
\hline Name & Catalog \# & Company & Application \\
\hline MTSS1 (N747) Ab & 43865 & Cell Signaling Technology & Immunoblotting \\
\hline Phospho-Zap-70 (Tyr319)/Syk (Tyr352) Ab & $2701 P$ & Cell Signaling Technology & Immunoblotting, microscopy \\
\hline Syk (D3Z1E) XP Rabbit mAb & 13198S & Cell Signaling Technology & Immunoblotting \\
\hline Phospho-Lyn (Tyr507) Ab & $2731 P$ & Cell Signaling Technology & Immunoblotting \\
\hline Lyn (C13F9) rabbit mAb & $2796 S$ & Cell Signaling Technology & Immunoblotting \\
\hline Phospho-CD19 (Tyr531) Ab & $3571 S$ & Cell Signaling Technology & Immunoblotting \\
\hline CD19 Ab & $3574 S$ & Cell Signaling Technology & Immunoblotting \\
\hline $\begin{array}{l}\text { Phospho-PI3 Kinase p85 (Tyr458)/p55 } \\
\text { (Tyr199) Ab }\end{array}$ & $4228 S$ & Cell Signaling Technology & Immunoblotting \\
\hline Phospho-CD19 (Tyr531) Ab & $3571 S$ & Cell Signaling Technology & Immunoblotting \\
\hline $\begin{array}{l}\text { Phospho-Akt (Ser473) (193H12) Rabbit } \\
\text { mAb }\end{array}$ & 4058S & Cell Signaling Technology & Immunoblotting \\
\hline Akt1 (C73H10) Rabbit mAb & $2938 S$ & Cell Signaling Technology & Immunoblotting \\
\hline $\begin{array}{l}\text { Phospho-NF-kappa-B p65 (Ser536) } \\
\text { (93H1) Rabbit mAb }\end{array}$ & $3033 S$ & Cell Signaling Technology & Immunoblotting \\
\hline NF-кB p65 (D14E12) XP ${ }^{\circledR}$ Rabbit mAb & $8242 S$ & Cell Signaling Technology & Immunoblotting \\
\hline p44/42 MAPK (Erk1/2) Ab & $9102 S$ & Cell Signaling Technology & Immunoblotting \\
\hline $\begin{array}{l}\text { Phospho-p44/42 MAPK (Erk1/2) } \\
\text { (Thr202/Tyr204) Ab }\end{array}$ & $9101 S$ & Cell Signaling Technology & Immunoblotting \\
\hline $\begin{array}{l}\text { Phospho-Btk (Tyr223) (D1D2Z) Rabbit } \\
\text { mAb }\end{array}$ & 87457 & Cell Signaling Technology & Immunoblotting \\
\hline $\begin{array}{l}\text { Peroxidase AffiniPure Goat Anti-Rabbit } \\
\operatorname{lgG}(\mathrm{H}+\mathrm{L})\end{array}$ & $111-035-144$ & Jackson ImmunoResearch & Immunoblotting \\
\hline $\begin{array}{l}\text { Peroxidase AffiniPure Goat Anti-Mouse } \\
\text { IgG, Fc } \gamma \text { Specific Ab }\end{array}$ & $115-035-071$ & Jackson ImmunoResearch & Immunoblotting \\
\hline $\begin{array}{l}\text { Donkey Anti-Rabbit IgG Ab, IRDye } 800 \\
\text { CW conjugated }\end{array}$ & $926-32213$ & LI-COR Biosciences & Immunoblotting \\
\hline AF555 Phalloidin & A34055 & Thermo Fisher Scientific & Microscopy \\
\hline $\begin{array}{l}\text { AF647 anti-mouse/human CD45R/B220 } \\
\text { Ab }\end{array}$ & 103229 & BioLegend & Microscopy \\
\hline Anti-Phosphotyrosine Ab, clone $4 \mathrm{G} 10^{\circledR}$ & $05-321$ & Merck Miilipore & Microscopy \\
\hline FITC Rat Anti-Mouse IgG2b & 553395 & $\mathrm{BD}$ & Microscopy \\
\hline CXCL13 & $250-24-5 \mu \mathrm{g}$ & PeproTech & Microscopy, SLB \\
\hline $\begin{array}{l}\text { AlexaFluor } 488 \text { Mouse Anti-Btk (pY223)/ltk } \\
\text { (pY180) }\end{array}$ & 564847 & BD Biosciences & Microscopy \\
\hline Donkey anti-rabbit lgG, AF488 conjugate & A-21206 & Thermo Fisher Scientific & Microscopy \\
\hline
\end{tabular}

$(-1),+139(+4),+143(+8)$, and $+150(+15)$. Coagulated blood was spun at $+4^{\circ} \mathrm{C} / 2,000 \mathrm{rpm}$ for $10 \mathrm{~min}$ and serum was collected and stored at $-20^{\circ} \mathrm{C}$.

All animal experiments were approved by the Ethical Committee for Animal Experimentation in Finland. They were done in adherence with the rules and regulations of the Finnish Act on Animal Experimentation (62/2006) and were performed according to the 3R-principle (animal license numbers: 7574/04.10.07/2014, KEK/2014-1407-Mattila, 10727/2018).

\section{ELISA}

Total and NP-specific antibody levels were measured by ELISA on half-area 96-well plates (Greiner Bio-One, 675061). Wells were coated overnight at $+4^{\circ} \mathrm{C}$ with capture antibodies $(2 \mu \mathrm{g} / \mathrm{ml})$ or NP-conjugated carrier proteins, $\mathrm{NP}_{(1-9)}$-BSA or $\mathrm{NP}_{(>20)}$-BSA $(\mathrm{N}-5050 \mathrm{~L}, \mathrm{~N}-5050 \mathrm{H}$, Biosearch Technologies) at $50 \mu \mathrm{g} / \mathrm{ml}$ in 25 $\mu \mathrm{l}$ PBS. Non-specific binding sites were blocked for $2 \mathrm{~h}$ in 150 $\mu \mathrm{l}$ of blocking buffer (PBS, $1 \% \mathrm{BSA}, 0.05 \% \mathrm{NaN}_{3}$ ). Appropriate, experimentally determined dilutions (see below) of $50-\mu 1$ serum samples in blocking buffer were added for overnight incubation at $+4^{\circ} \mathrm{C}$. Biotin-conjugated detection antibodies $(2 \mu \mathrm{g} / \mathrm{ml})$ in $50 \mu \mathrm{l}$ of blocking buffer were added for $1 \mathrm{~h}$ followed by $50 \mu \mathrm{l}$ ExtrAvidin-Alkaline phosphatase (E2636, Sigma-Aldrich, 1:5,000 dilution) in blocking buffer for $1 \mathrm{~h}$ at room temperature (RT). In between all incubation steps, plates were washed with 150 $\mu l$ washing buffer (PBS, 0.05\% Tween-20) either three times for the steps before sample addition or six times after addition of the mouse sera. The final wash was completed by washing two times with $150 \mu \mathrm{l}$ of water. Finally, $50 \mu \mathrm{l}$ of alkaline phosphatasesubstrate, SIGMAFAST p-nitrophenyl phosphate (N2770, SigmaAldrich) solution was added and OD was measured at $405 \mathrm{~nm}$. Serum dilutions were determined experimentally to fall into the linear part of the dose-response curve of the absorbance 
measurements for any given isotype and typical values are as follows: IgM levels (1:3,000-1:4,000), IgG levels (1:20,000$1: 80,000)$. Different dilutions of AP-streptavidin were used where necessary. Typical time for AP-substrate incubation before measurement was about $30 \mathrm{~min}$ at RT.

All ELISA samples were run in duplicates, OD values were averaged and blank background was subtracted. Absolute concentrations of total antibody levels were extrapolated from calibration curves prepared by serial dilution of mouse IgM or subclasses of IgG from C57Bl/6 immunoglobulin panel. Relative NP-specific antibody levels were extrapolated from reference curves prepared by serial dilution of pooled serum, in which the highest dilution step received an arbitrary unit of 0.5 .

\section{Immunophenotyping}

All cells were isolated in B cell isolation buffer (PBS, 2\% FCS, $1 \mathrm{mM}$ EDTA). Bone marrow cells were isolated by flushing the buffer through mouse femoral and tibial bones. Splenocytes were isolated by mashing the spleen in small buffer volumes with syringe plunger in 48-well plates. Peritoneal cavity cells were isolated by filling the cavity with $\sim 10 \mathrm{ml}$ buffer volume through puncture and collecting the fluid back. Cell suspensions were filtered through $70-\mu \mathrm{m}$ nylon cell strainers. As a general flow cytometry protocol, all subsequent steps were done in flow cytometry buffer I (PBS, 1\% BSA). Fc-block was done with 0.5 $\mu \mathrm{l}$ of anti-mouse CD16/32 antibodies in $70 \mu \mathrm{l}$ of flow cytometry buffer I for $10 \mathrm{~min}$ and cells were stained for $30 \mathrm{~min}$. Washings were done three times in $150 \mu$ l of flow cytometry buffer I. All steps were carried out on ice in U-bottom 96-well plates at a cell density of $0.25-0.5 \times 10^{6} /$ well. Before acquisition, cells were resuspended in $130 \mu \mathrm{l}$ of flow cytometry buffer II (PBS, $2.5 \%$ FCS). Samples were acquired on BD LSR Fortessa, equipped with four laser lines (405, 488, 561, and $640 \mathrm{~nm})$. Compensation matrix was calculated and applied to samples either in BD FACSDiva $^{\mathrm{TM}}$ software (BD Biosciences) or in FlowJo (Tree Star, Inc) based on fluorescence of conjugated antibodies using compensation beads (01-1111-41, Thermo Fisher Scientific). FMO (fluorescence minus one) controls were used to assist gating. Data were analyzed with FlowJo software.

\section{B Cell Isolation}

Splenic B cells were Isolated with EasySep ${ }^{\mathrm{TM}}$ Mouse B Cell Isolation Kit (19854, Stem Cells Technologies) according to the manufacturer's instructions and let to recover in RPMI (10\% FCS, $20 \mathrm{mM}$ HEPES, $50 \mu \mathrm{M} \beta$-mercaptoethanol, 1:200 Pen/Strep) in an incubator at $+37^{\circ} \mathrm{C}$ and $5 \% \mathrm{CO}_{2}$ for $1-2 \mathrm{~h}$.

\section{Class-Switch Recombination and Proliferation}

Isolated splenic B cells $\left(\sim 10-20 \times 10^{6}\right.$ cells $)$ were stained first with $5 \mu \mathrm{l}(5 \mathrm{mM})$ of Cell Trace Violet (C34557, Thermo Fisher Scientific) in $10 \mathrm{ml}$ of PBS for $10 \mathrm{~min}$ at RT and let to recover in complete RPMI $\left(+37^{\circ} \mathrm{C}, 5 \% \mathrm{CO}_{2}\right)$ for $1-2 \mathrm{~h}$. To induce classswitching, B cells were cultured on 24 -well plates at $0.5 \times$ $10^{6} / \mathrm{ml}$ density in complete RPMI supplemented with indicated doses of LPS $(4 \mu \mathrm{g} / \mathrm{ml})$, CD $40 \mathrm{~L}(150 \mathrm{ng} / \mathrm{ml})$, IL-4 $(5 \mathrm{ng} / \mathrm{ml})$, IFN- $\gamma(100 \mathrm{ng} / \mathrm{ml})$, and TGF- $\beta$ ( $3 \mathrm{ng} / \mathrm{ml})$ for 3 days. Cells were blocked with anti-mouse anti-CD16/32 and stained for $30 \mathrm{~min}$ with antibodies against IgG subclasses. Additionally, cells were stained with $4 \mu \mathrm{g} / \mathrm{ml}$ 7-AAD (ABD-17501, Biomol) for live/dead cell discrimination and samples were acquired on BD LSR II equipped with three laser lines $(405,488$, and $640 \mathrm{~nm})$ and analyzed with FlowJo software.

\section{BCR Signaling and Immunoblotting}

For analysis of BCR signaling, isolated splenic B cells were starved for $10 \mathrm{~min}$ in plain RPMI and $0.5 \times 10^{6}$ cells in 100 $\mu l$ of plain RPMI were stimulated in duplicates with antimouse IgM $\mu$-chain-specific (anti-IgM) antibodies, or their $\left.\mathrm{F}(\mathrm{ab})^{\prime}\right)_{2}$ fragments, either in solution or bound to the culture dish surface, for 3, 7, and $15 \mathrm{~min}$. For solution stimulation, $5 \mu \mathrm{g} / \mathrm{ml}$ of anti-IgM was used, in 96-well plates. For surfacebound mode, 48 -well plates were coated with $5 \mu \mathrm{g} / \mathrm{ml}$ of anti-IgM antibodies in $120 \mu \mathrm{l}$ of PBS at $+4^{\circ} \mathrm{C}$, overnight, and washed three times with $500 \mu \mathrm{l}$ of ice-cold PBS before experiment. Equimolar concentrations of $\mathrm{F}\left(\mathrm{ab}^{\prime}\right)_{2}$ fragments were used for soluble stimulations and coating for surface-bound stimulations. After activation, B cells were instantly lysed with $25 \mu$ l of $5 \times$ SDS lysis buffer (final: $62.5 \mathrm{mM}$ Tris- $\mathrm{HCl}, \mathrm{pH} \sim 6.8,2 \%$ SDS, $10 \%$ glycerol, $100 \mathrm{mM} \beta$-mercaptoethanol, and bromophenol blue) and sonicated for $7.5 \mathrm{~min}$ (1.5- $\mathrm{ml}$ tubes, high power, $30 \mathrm{~s}$ on/off cycle, Bioruptor plus, Diagenode). Lysates (20-30 $\mu \mathrm{l})$ were run on $8-10 \%$ polyacrylamide gels and transferred to PVDF membranes (Trans-Blot Turbo Transfer System, Bio$\mathrm{Rad}$ ). Membranes were blocked with 5\% BSA in TBS (TBS, pH $\sim 7.4)$ for $1 \mathrm{~h}$ and incubated with primary antibodies $(\sim 1: 1,000)$ in $5 \%$ BSA in TBST (TBS, $0.05 \%$ Tween-20) at $+4^{\circ} \mathrm{C}$, overnight. Secondary antibody incubations $(1: 20,000)$ were done for $2 \mathrm{~h}$ at RT in 5\% milk in TBST for HRP-conjugated antibodies and with addition of $0.01 \%$ SDS for fluorescently conjugated antibodies. Washing steps were done in $10 \mathrm{ml}$ of TBST for $5 \times$ 5 min. Membranes were scanned with Odyssey CLx (LI-COR) or visualized with Immobilon Western Chemiluminescent HRP Substrate (WBKLS0500, Millipore) and ChemiDoc MP Imaging System (Bio-Rad). Phospho-antibodies were stripped in $25 \mathrm{mM}$ glycine- $\mathrm{HCl}$ buffer, $\mathrm{pH} \sim 2.5$, for $10 \mathrm{~min}$, and membranes were blocked and probed again for evaluation of total protein levels. Images were background subtracted and the raw integrated densities for each band were measured in ImageJ. Ratios of phosphorylated-vs.-total protein levels were analyzed with ratio paired $t$-test. For data presentation, these ratios were normalized to $\mathrm{WT}$ value at $0 \mathrm{~min}$.

\section{Intracellular $\mathrm{Ca}^{2+}$ Flux}

Splenic B cells were resuspended at a concentration of 2.5-5 $\times 10^{6} \mathrm{cell} / \mathrm{ml}$ in RPMI supplemented with $20 \mathrm{mM}$ HEPES and 2.5\% FCS and loaded with $1 \mu \mathrm{M}$ Fluo-4 (F14201, Thermo Fisher Scientific) and $3 \mu \mathrm{M}$ Fura Red (F3021, Thermo Fisher Scientific) for $45 \mathrm{~min}\left(+37^{\circ} \mathrm{C}, 5 \% \mathrm{CO}_{2}\right)$. Cell suspension was diluted in 10 volumes of complete RPMI and incubated for 10-15 min at RT. Cells were centrifuged at $200 \mathrm{~g}$, at RT for $5 \mathrm{~min}$ and resuspended at $2.5 \times 10^{6}$ cells $/ \mathrm{ml}$ in PBS supplemented with $20 \mathrm{mM}$ HEPES, $5 \mathrm{mM}$ glucose, $0.025 \%$ BSA, $1 \mathrm{mM} \mathrm{CaCl}_{2}, 0.25 \mathrm{mM}$ sulfinpyrazone (S9509, Sigma-Aldrich), and 2.5\% FCS. Cells were 
allowed to rest at RT for $20 \mathrm{~min}$ and were kept on ice before acquisition. Anti-IgM antibodies were added into prewarmed $\left(+37^{\circ} \mathrm{C}, 5 \mathrm{~min}\right) \mathrm{B}$ cell suspension aliquots to final concentrations of $10,5,2.5$, and $1 \mu \mathrm{g} / \mathrm{ml}$ and samples were acquired on $\mathrm{BD}$ LSR Fortessa. Alternatively, equimolar concentrations of anti$\operatorname{IgM~F}\left(\mathrm{ab}^{\prime}\right)_{2}$ fragment were used. Fluorescence of Fluo-4 and Fura Red were recorded by a continuous flow for $5 \mathrm{~min}$. Data were analyzed in FlowJo and presented as ratiometric measurement of Fluo-4/Fura Red median intensity levels.

Peritoneal cavity B cells were washed in L-15 medium, resuspended in $75 \mu \mathrm{l}$ acquisition buffer [HBS (HEPES buffered saline):L-15 (1:1 ratio), $2.5 \mu \mathrm{M}$ probenecid (P8761, SigmaAldrich)] and labeled by addition of $75 \mu \mathrm{l}$ of acquisition buffer with $10 \mu \mathrm{M}$ Fluo- 4 for $5 \mathrm{~min}$ at $+37^{\circ} \mathrm{C}$. Cells were washed in $1 \mathrm{ml}$, resuspended in $200 \mu \mathrm{l}$ and divided into two wells. B cells were prestained for $10 \mathrm{~min}$ on ice with anti-CD23-AlexaFluor (AF)-594 antibodies, washed and resuspended in $100 \mu \mathrm{l}$ of acquisition buffer on ice. Samples were prewarmed $\left(+37^{\circ} \mathrm{C}\right)$ in a total volume of $300 \mu \mathrm{l}$ of acquisition buffer and $50 \mu \mathrm{l}$ of anti$\operatorname{IgM~F}\left(\mathrm{ab}^{\prime}\right)_{2}-\mathrm{AF} 633$ were added. Cells were acquired on BD LSR Fortessa for 3-5 min and analyzed in FlowJo.

\section{Scanning Electron Microscopy}

For the analysis of resting B cells, wells of the microscopy slides (10028210, Thermo Fisher Scientific) were coated with CellTak (354240, Corning) in PBS $\left(3.5 \mu \mathrm{g} / \mathrm{cm}^{2}\right.$ of surface area, according to manufacturer's recommendations) for $20 \mathrm{~min}$ (RT), washed once with water and allowed to dry. For the analysis of activated B cells, wells were coated with $5 \mu \mathrm{g} / \mathrm{ml}$ of anti-IgM in PBS for $1 \mathrm{~h}$ (RT) and washed in PBS. $10^{5} \mathrm{~B}$ cells in $20 \mu \mathrm{l}$ of complete RPMI were placed on coated wells for $10 \mathrm{~min}\left(+37^{\circ} \mathrm{C}, 5 \% \mathrm{CO}_{2}\right)$ and fixed by adding $20 \mu \mathrm{l}$ PFA in PBS (4\% PFA final, $\mathrm{pH} 7.0-$ 7.5) for $15 \mathrm{~min}$. Samples were further fixed in $4 \% \mathrm{PFA} / 2.5 \%$ gluteraldehyde in PBS for $30 \mathrm{~min}$, washed in PBS and postfixed in $1 \% \mathrm{OsO}_{4}$ containing $1.5 \%$ potassium ferrocyanide, and dehydrated with a series of increasing ethanol concentrations (30, $50,70,80,90,96$, and twice 100\%). Specimens were immersed in hexamethyldisilazane and left to dry by solvent evaporation. The cells were coated with carbon using Emscope TB 500 Temcarb carbon evaporator and imaged with Leo 1530 Gemini scanning electron microscope.

\section{Immunofluorescence Microscopy and Cell Spreading TIRF Microscopy}

MatTek microscopy dishes were coated with $7.5 \mu \mathrm{g} / \mathrm{ml}$ of antiIgM antibodies in PBS at $+37^{\circ} \mathrm{C}$ for $30 \mathrm{~min}$ and washed once with PBS. Isolated splenic B cells $\left(10^{6}\right)$ were left unstained or labeled with $0.17 \mu \mathrm{l}$ of anti-B220-AF647 antibodies in $400 \mu \mathrm{l}$ PBS for $10 \mathrm{~min}$ in $1.5 \mathrm{ml}$ tubes on ice, spun (2,500 rpm, $5 \mathrm{~min}$ ), washed twice in $900 \mu \mathrm{l}$ of ice-cold PBS and resuspended in 200 $\mu \mathrm{l}$ of Imaging buffer (PBS, 10\% FBS, $5.5 \mathrm{mM}$ D-glucose, $0.5 \mathrm{mM}$ $\mathrm{CaCl}_{2}$, and $0.2 \mathrm{mM} \mathrm{MgCl}_{2}$ ). Equal amounts of unstained and labeled cells of different genotypes were mixed and loaded onto coated MatTek dishes at $35 \mu \mathrm{l} /$ well. Cells were incubated for $10 \mathrm{~min}\left(+37^{\circ} \mathrm{C}, 5 \% \mathrm{CO}_{2}\right)$, fixed in pre-warmed $\left(+37^{\circ} \mathrm{C}\right) 4 \%$ formaldehyde/PBS for $10 \mathrm{~min}$ (RT), permeabilized in $0.1 \%$ Triton $\mathrm{X}-100 / \mathrm{PBS}$ for $5 \mathrm{~min}$ (RT), washed once with PBS, and blocked in blocking buffer (PBS, $1 \%$ BSA) at $+4^{\circ} \mathrm{C}$ (overnight). Cells were stained with 1:50 Phalloidin-AF555 and 1:500 anti-pTyr primary antibody (4G10) in blocking buffer for $1 \mathrm{~h}(\mathrm{RT})$, washed four times with PBS, and stained with 1:500 secondary antimouse IgG2b-AF488 in blocking buffer for $1 \mathrm{~h}$ (RT), washed four times in PBS, and imaged in PBS with total internal reflection fluorescence (TIRF) mode in DeltaVision OMX Imaging System (GE Healthcare). TIRF images of cortical actin and pTyr were processed with ImageJ macro using B220 and bright-field channels to discriminate between attached WT or MIM-KO cells. Spreading area (determined on pTyr channel), mean fluorescence intensity, and total fluorescence intensity (integrated density) of phalloidin and pTyr staining of each cell were analyzed $(\sim 50-$ 340 cells per sample). For cumulative scatter plots, equal numbers (here 92 cells) were randomly selected from each experiment.

\section{Spinning Disk Confocal Microscopy}

Twelve-well PTFE diagnostic slides (Thermo Fisher Scientific, $\# 10028210$ ) were coated with $5 \mu \mathrm{g} / \mathrm{ml}$ anti-mouse IgM $(\mu$ chain-specific antibodies) in PBS at $+4^{\circ} \mathrm{C} \mathrm{O} / \mathrm{N}$ and washed with PBS. As a non-activated control, wells were coated with $4 \mu \mathrm{g} / \mathrm{ml}$ fibronectin. Isolated splenic B cells $\left(10^{6} / \mathrm{ml}\right)$ were labeled with $1 \mu \mathrm{M}$ CFSE (21888, Sigma-Aldrich) or left unlabeled. Equal amounts of unstained and labeled cells of different genotypes were mixed (1:1 ratio) and seeded at a density of 100,000 cells/well. Dye-switched experiments were performed systematically. Cells were incubated for 3, 5, 7, 10, or $15 \mathrm{~min}$ $\left(+37^{\circ} \mathrm{C}, 5 \% \mathrm{CO}_{2}\right)$, fixed in $4 \%$ formaldehyde/PBS for $10 \mathrm{~min}$ (RT), and permeabilized/blocked in $0.3 \%$ Triton $\mathrm{X}-100 / 5 \%$ donkey serum/PBS for $20 \mathrm{~min}$ (RT). Staining was performed in $0.3 \%$ Triton $\mathrm{X}-100 / 1 \% \mathrm{BSA} / \mathrm{PBS}$ at $+4^{\circ} \mathrm{C} \mathrm{O} / \mathrm{N}$, followed by washes with $\mathrm{PBS}$ and incubation with the secondary antibodies for $30 \mathrm{~min}$ at room temperature in PBS. Samples were mounted in FluoroMount-G (Thermo Fisher Scientific). Images were acquired on $3 \mathrm{i}$ CSU-W1 (Intelligent Imaging Innovations) Marianas spinning disk confocal microscope equipped with $63 \times$ Zeiss Plan-Apochromat objective and a Photometrics Prime BSI sCMOS camera. Cells were visualized at the plane of contact and 5-10 fields of view per sample were acquired. Images of F-actin, pBtk, and pSyk were processed with ImageJ using CTV channel to discriminate between WT or MIM-KO cells. Spreading area (determined on the phalloidin channel) and mean fluorescence intensity of pBtk or pSyk staining per cell were analyzed ( $\sim 25-$ 150 cells per condition per experiment).

\section{Supported Lipid Bilayers}

Artificial planar lipid bilayers containing GPI-linked mouse ICAM-1 (200 molecules/ $\left.\mu \mathrm{m}^{2}\right)$ were formed as previously described (20, 21). Briefly, unlabeled GPI-linked ICAM-1 liposomes and liposomes containing biotinylated lipids were mixed with 1,2-dioleoyl-PC (DOPC) (850375P, Avanti lipids, Inc) at various ratios to obtain specified molecular densities. Planar membranes were assembled on FCS2 dosed chambers (Bioptechs) and blocked with PBS/2\% FCS for $1 \mathrm{~h}$ at RT. Antigen was tethered by incubating membranes with AF647streptavidin, followed by monobiotinylated anti-kappa light chain antibodies $\left(20\right.$ molecules $\left./ \mu \mathrm{m}^{2}\right)$. The isolated B cells from WT and $\mathrm{MIM}^{-/-}$mice were labeled with $1 \mu \mathrm{M}$ 
CFSE (21888, Sigma-Aldrich) or left unlabeled, mixed at 1:1 ratio, and injected into prewarmed chambers $(4 \times$ $10^{6}$ cells/chamber, $+37^{\circ} \mathrm{C}$ ) with $100 \mathrm{nM}$ recombinant murine CXCL13. Fluorescence, differential interference contrast (DIC), and interference reflection microscopy (IRM) images were acquired at the plane of the cell contact in one position once every $30 \mathrm{~s}$ immediately after injecting the cells into the chamber for $10 \mathrm{~min}$. After the 10 -min movie was acquired, several snapshots were acquired for quantification of the mature synapses in different locations of the chamber at 10-15 min after cell injection. All assays were performed in PBS, supplemented with $0.5 \%$ FCS, $0.5 \mathrm{~g} / \mathrm{L}$ D-glucose, $2 \mathrm{mM} \mathrm{MgCl}$, and $0.5 \mathrm{mM}$ $\mathrm{CaCl}_{2}$. Images were acquired on a Zeiss Axiovert LSM 510META inverted microscope, equipped with $40 \times$ oil-immersion objective (Madrid), or a Zeiss LSM 780 inverted microscope, equipped with $40 \times$ water-immersion objective (Turku), and analyzed by ImageJ. The spreading area (determined on IRM channel), area of collected antigen, and mean fluorescence intensity of antigen were quantified from each experiment $(\sim 100$ cells per experiment).

\section{Intracellular $\mathrm{Ca}^{2+}$ Flux on Supported Lipid Bilayers}

Splenic WT or $\mathrm{MIM}^{-/-}$B cells $\left(3.2 \times 10^{6}\right)$ were resuspended in $75 \mu \mathrm{l}$ of L-15 medium and labeled by addition of $75 \mu \mathrm{l}$ of HBS (HEPES buffered saline), supplemented with $2.5 \mu \mathrm{M}$ probenecid and $20 \mu \mathrm{M}$ Fluo 4 for $5 \mathrm{~min}$ at $+37^{\circ} \mathrm{C}$. Cells were washed in $1 \mathrm{ml}$ of HBS-probenecid and resuspended in 500 $\mu l$ of HBS-probenecid for immediate injection into FCS2 chambers. Acquired movies were preprocessed with ImageJ and analyzed with a MATLAB-implemented high-throughput software CalQuo ${ }^{2}$ (22). Cells were categorized as single peak, oscillatory, or not triggering. Cells showing more than two intensity peaks are classified as oscillatory. Data presented as mean percentages of three independent experiments with at least 1,000 cells analyzed per experiment.

\section{Metabolic Assay}

Splenic B cells were seeded at a density of $10^{6}$ cells $/ \mathrm{ml}$ in complete RPMI and treated with indicated combinations of IL-4 $(10 \mathrm{ng} / \mathrm{ml})$, anti-mouse IgM $(10 \mu \mathrm{g} / \mathrm{ml})$, LPS $(4 \mu \mathrm{g} / \mathrm{ml})$, and CpG $(10 \mu \mathrm{g} / \mathrm{ml})$ for $24 \mathrm{~h}$ at $+37^{\circ} \mathrm{C}, 5 \% \mathrm{CO}_{2}$ in a humidified incubator. Cells were then spun and resuspended in Seahorse XF RPMI (103576-100, Agilent), supplemented with $1 \mathrm{mM}$ pyruvate, $2 \mathrm{mM}$ L-glutamine, and $10 \mathrm{mM}$ D-glucose. Cell number was adjusted and $0.15 \times 10^{6}$ cells were seeded per well on a 96-well XF plate, pre-coated with CellTak (354240, Corning). Plate coating was done with $22.4 \mu \mathrm{g} / \mathrm{ml}$ CellTak in $\mathrm{NaHCO}_{3}, \mathrm{pH} 8.0$, at $+4^{\circ} \mathrm{C}$ overnight, followed by two washings with water. Seeded cells were spun at $200 \mathrm{~g}$ for $1 \mathrm{~min}$ with no break and left for $1 \mathrm{~h}$ at $37^{\circ} \mathrm{C}$ to attach to coated wells in a humidified incubator without $\mathrm{CO}_{2}$ to avoid medium acidification. Seahorse XF96 plate (101085-004, Agilent) was used following the manufacturer's instructions for XF Cell Mito Stress Test Kit (103015-100, Agilent). In this test, sequentially, $1 \mu \mathrm{M}$ oligomycin, $2 \mu \mathrm{M}$ FCCP, and $0.5 \mu \mathrm{M}$ rotenone/antimycin $\mathrm{A}$ were added to the media. Oxygen consumption rate (OCR) and extracellular acidification rate (ECAR) data were recorded by WAVE software (Agilent). OCR and ECAR data were normalized to cell count and first baseline measurement of WT cells. Basal, maximum, and spare respiratory capacities were extracted with area under curve analysis in GraphPad Prism.

\section{Analysis of Mitochondria}

For TMRE staining, B cells were washed in $150 \mu \mathrm{l}$ PBS, stained with 1:500 Zombie Violet for dead cell discrimination in PBS on ice, washed $2 \times 100 \mu \mathrm{l}$ with complete RPMI, and stained with $5 \mathrm{nM}$ TMRE (T669, Thermo Fisher Scientific) in $200 \mu \mathrm{l}$ of complete RPMI at RT for 20 min. Resuspended in $150 \mu \mathrm{l}$ of complete RPMI, cells were immediately analyzed by flow cytometry, on BD LSR Fortessa.

For Tom 20 staining, B cells were stained with Zombie Violet as described above, fixed with $1.6 \%$ formaldehyde in PBS for $10 \mathrm{~min}$, washed $2 \times 150 \mu \mathrm{l}$ PBS, permeabilized with $0.1 \%$ Triton $\mathrm{X}-100$ in PBS for $5 \mathrm{~min}$ at RT, and blocked for $1 \mathrm{~h}$ at RT. Incubation with primary Tom 20 antibodies was done at 1:500 dilution for $30 \mathrm{~min}$, followed by $3 \times 150 \mu \mathrm{l}$ washes, staining with 1:1,000 dilution of anti-rabbit-AF488 secondary antibodies, and $3 \times 150 \mu \mathrm{l}$ washes. Cells were then resuspended in $130 \mu \mathrm{l}$ and analyzed by flow cytometry, on BD LSR Fortessa. Antibody incubations, blocking, and washings were done in flow cytometry buffer I on ice. Geometric mean fluorescence intensities were extracted with FlowJo software.

\section{Statistics and Data Presentation}

Statistical analysis was performed in GraphPad Prism. Student's $t$-test was applied to the data comparing WT and MIM-KO groups. Antibody titers and microscopy data were analyzed with unpaired two-tailed $t$-test unless otherwise stated. Additionally, for TIRF microscopy datasets, geometric means were extracted for each biological replicate and means were analyzed by ratio paired $t$-test. In all other experiments, where pairing of WT and MIM-KO data was based on the day of the experiment, ratio paired $t$ test was also applied. Multiple-measures twoway ANOVA was additionally used to compare the antibody responses upon immunization. Data presented as mean $\pm \mathrm{SEM}$, unless stated otherwise. Significance is denoted as ${ }^{*} p<0.05$, ${ }^{* *} p<0.01,{ }^{* * *} p<0.001,{ }^{* * * *} p<0.0001$. Inkscape and Adobe Illustrator were used for figure assembly, and Biorender was used for schematics.

\section{RESULTS}

\section{Largely Normal B Cell Development and Maturation of B Cells in MIM-/- Mice $^{-/}$}

Mice with targeted disruption of $M t s s 1$ gene $\left(\mathrm{MIM}^{-/-}\right)$, lacking the expression of MIM, were generated previously (18). Splenic B cells, which normally show robust MIM staining in immunoblot, isolated from these mice showed no detectable MIM expression (Figure 1A). To investigate the possible functions of MIM in the B cell compartments, we first examined the $\mathrm{B}$ cells in the bone marrow. We notified a slightly increased number of hematopoietic progenitors, as defined by $\mathrm{CD}_{117^{+}} \mathrm{CD}^{-} 9^{-}$cells but found no apparent differences in the numbers of $\mathrm{CD}_{19}{ }^{+}$and $\mathrm{CD}^{+} 9^{+} \mathrm{IgM}^{+}$ 


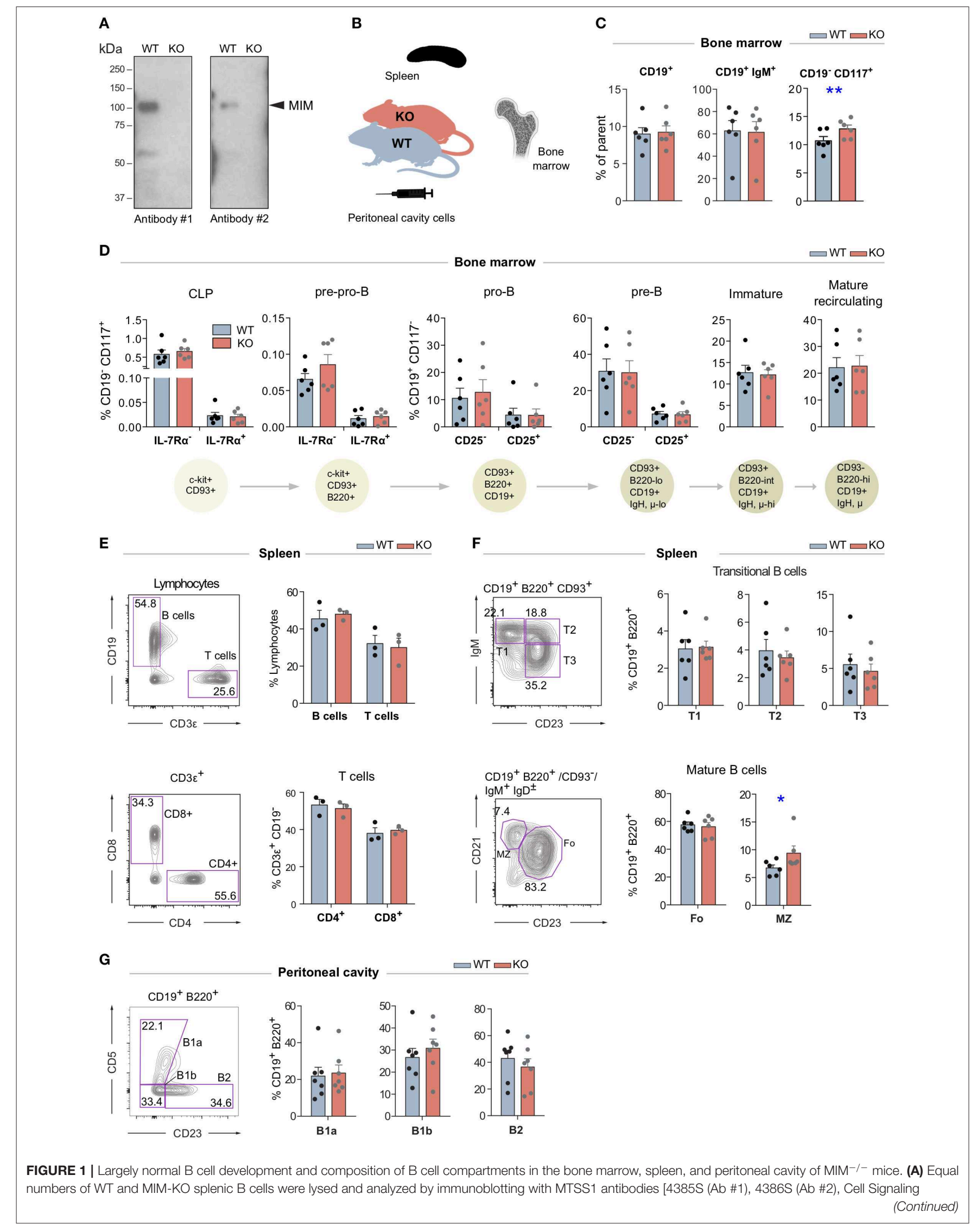


FIGURE 1 | Technology]. Arrowhead indicates the position of the band corresponding to MIM. (B) Bone marrow, spleen, and peritoneal cavity cell populations from WT and $\mathrm{MIM}^{-/-}$mice were extracted for analysis by flow cytometry (C-G) using the gating strategy shown in Supplementary Figures S1, S2. Data of three to six independent experiments are shown as mean \pm SEM. (C) Percentages of total CD19 ${ }^{+}, \mathrm{CD} \mathrm{9}^{+}$IgM $^{+}$, and CD19- $\mathrm{CD}^{-117^{+}}$cells in the bone marrow. (D) Percentages of B cell precursor and mature recirculating B cell populations in the bone marrow. Progression through consecutive B cell developmental stages was analyzed based on the major surface phenotypic markers shown in the schematic below. Percentage of corresponding bone marrow populations are shown as mean \pm SEM. (E) Percentages of CD19 ${ }^{+}$B cells and total (upper panel) as well as CD4 ${ }^{+}$and CD8 ${ }^{+}$T cell populations (lower panel) in the spleen. (F) Percentages of major B cell subsets in the spleen. T1-3 (transitional 1-3), Fo (follicular), MZ (marginal zone) B cells are analyzed. (G) Percentages of CD23- CD5+ (B1a), CD23- CD5- (B1b), and $\mathrm{CD}^{2} 3^{+} \mathrm{CD}^{-}$(B2) B cells in the peritoneal cavity. Mean \pm SEM is shown. ${ }^{*} p<0.05,{ }^{* *} p<0.01$.

populations between age-matched wild type (WT) and $\mathrm{MIM}^{-/-}$ mice (Figures 1B,C and Supplementary Figure S1B). We then carried out more detailed analysis of the bone marrow $\mathrm{B}$ cells with additional surface markers to resolve consecutive developmental stages from common lymphoid progenitors to immature and mature recirculating B cells (gating strategy shown in Supplementary Figure S1A). We found no significant differences between WT and $\mathrm{MIM}^{-/-}$mice in any of these developmental stages (Figure 1D).

Next, we went on to analyze the maturation of B cells and their different subsets in the periphery (gating strategy shown in Supplementary Figures S2A,B). No defects were observed in the overall percentages of $\mathrm{CD}_{1}{ }^{+} \mathrm{B}$ cells or major $\mathrm{T}$ cell subsets in the spleen (Figure 1E). Also, the proportions of transitional (T1-3) and follicular (Fo) cells were not significantly altered, while marginal zone (MZ) B cells appeared slightly elevated (Figure 1F). A special self-renewing population of B cells concentrate in the peritoneal and pleural cavities. To analyze these B1 cells, we isolated cells from the peritoneal cavity of $\mathrm{MIM}^{-/-}$and WT mice. We found no significant differences in the proportions of $\mathrm{CD}^{+}(\mathrm{B} 1 \mathrm{a}), \mathrm{CD}^{-}$(B1b) or mature peritoneal B cells (B2) (Figure 1G). These results demonstrate that the development of different B cell subsets, both in the bone marrow as well as in the periphery, does not depend on MIM.

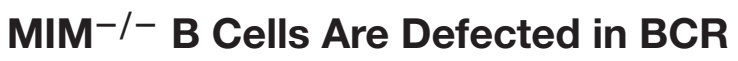 Signaling Upon Activation With Surface-Bound Antigens}

Previous cell biological studies in other cell types, supported by various biochemical assays, have proposed a role for MIM at the interface of the plasma membrane and the actin cytoskeleton $(6,7,10,18,19,23)$. The actin cytoskeleton is intimately involved in the activation of B cells on antigen-presenting cells by enabling the spreading of the cells and the formation of the immunological synapse (24). Interestingly, the organization of the plasma membrane and the actin cytoskeleton have also been shown to regulate the signaling capacity of the BCR (1, $3,4)$. To examine the role of MIM in BCR signaling, we, first, analyzed the mobilization of intracellular calcium, one of the most dramatic immediate consequences of BCR triggering. We isolated splenic B cells from WT and $\mathrm{MIM}^{-/-}$mice, loaded them with Fluo-4 and Fura Red, and stimulated them with decreasing concentrations of surrogate antigen, either full antibodies against mouse IgM BCR (anti-IgM), or their $\mathrm{F}\left(\mathrm{ab}^{\prime}\right)_{2}$ fragments, while analyzing the response by flow cytometry. Ratiometric analysis of Fluo-4/Fura Red fluorescence intensities revealed similar elevation of intracellular $\mathrm{Ca}^{2+}$ levels in both WT and $\mathrm{MIM}^{-/-} \mathrm{B}$ cells (Figure 2A and Supplementary Figure S3F).
We also analyzed the calcium response in peritoneal cavity B cells, which were loaded with Fluo-4, prestained with CD23Alexa Fluor (AF)-594 just before acquisition, and stimulated with AF633-labeled anti-IgM antibodies, allowing distinction between B1 $\left(\operatorname{IgM}^{+} \mathrm{CD} 23^{-}\right)$and B2 $\left(\operatorname{IgM}^{+} \mathrm{CD}^{+} 3^{+}\right)$cells. Intracellular $\mathrm{Ca}^{2+}$ mobilization was found comparable between WT and $\mathrm{MIM}^{-/-}$cells also in these two B cell subsets (Supplementary Figure S3A).

To study the BCR signaling in more detail, we next analyzed activation of individual components of BCR signaling pathway by looking at phosphorylation levels of downstream effector molecules. Splenic B cells were stimulated with soluble or surfacebound anti-IgM antibodies for 3, 7, and $15 \mathrm{~min}$ and analyzed by immunoblotting. As expected, both stimulatory conditions induced rapid activation of BCR signaling components, as detected by the levels of phosphorylated signaling proteins. Importantly, $\mathrm{MIM}^{-/-} \mathrm{B}$ cells showed clear defects in signaling in response to surface-bound anti-IgM. Most of the analyzed molecules, including Syk, CD19, Btk, p65 NF- $\kappa$ B, and MAPK1/2, showed significant reduction in their activation (Figures $2 B, C$ ). Consistently, we found similar differences when using either 5 or $1 \mu \mathrm{g} / \mathrm{ml}$ of surface-tethered anti-IgM, or corresponding amounts of $\mathrm{F}\left(\mathrm{ab}^{\prime}\right)_{2}$ fractions of anti-IgM (Supplementary Figures S3D,E). The signaling components studied can be classified into different cascades from the proximal players to downstream effectors. While MIM $^{-/-}$cells showed robust defects in proximal signaling molecules, the extent to which they affected the downstream cascades alternated. The defects in CD19-PI3K pathway were recovered at the level of Akt. At the same time, the levels of pp65 NF- $\mathrm{B}$ and pMAPK1/2 were decreased, suggesting that $\mathrm{MIM}^{-/-} \mathrm{B}$ cells were inefficient in triggering the diacylglycerol (DAG)-PKC module, which targets both NF- $\mathrm{B}$ and MAPK1/2 (25). Interestingly, when we studied activation of BCR by a soluble ligand, anti-IgM surrogate antibodies in solution, $\mathrm{MIM}^{-/-}$B cells only showed significant defects in the activation of the proximal kinase Syk, but normal activation of other signaling components (Supplementary Figures S3B,C). These results place MIM as a regulator of, specifically, BCR signaling by surface-bound antigen, a function that clearly depends on the fine-tuned activities of the actin cytoskeleton (26) and could fit well with the previously postulated role of MIM as an organizer of the actin cytoskeleton-membrane interface.

\section{The Morphology and Formation of the Immunological Synapse Is Unaltered in MIM-/- B Cells $^{-1}$}

The actin cytoskeleton is one of the major organizers of cell shape. To explore whether $\mathrm{MIM}^{-/-} \mathrm{B}$ cells showed any 


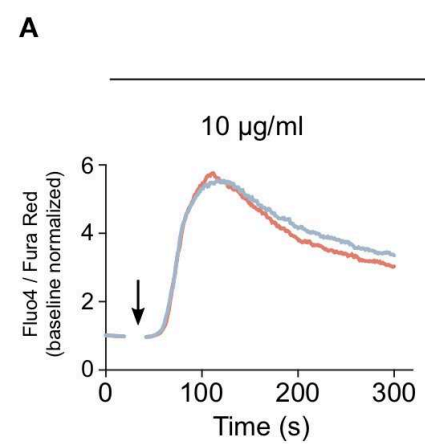

B

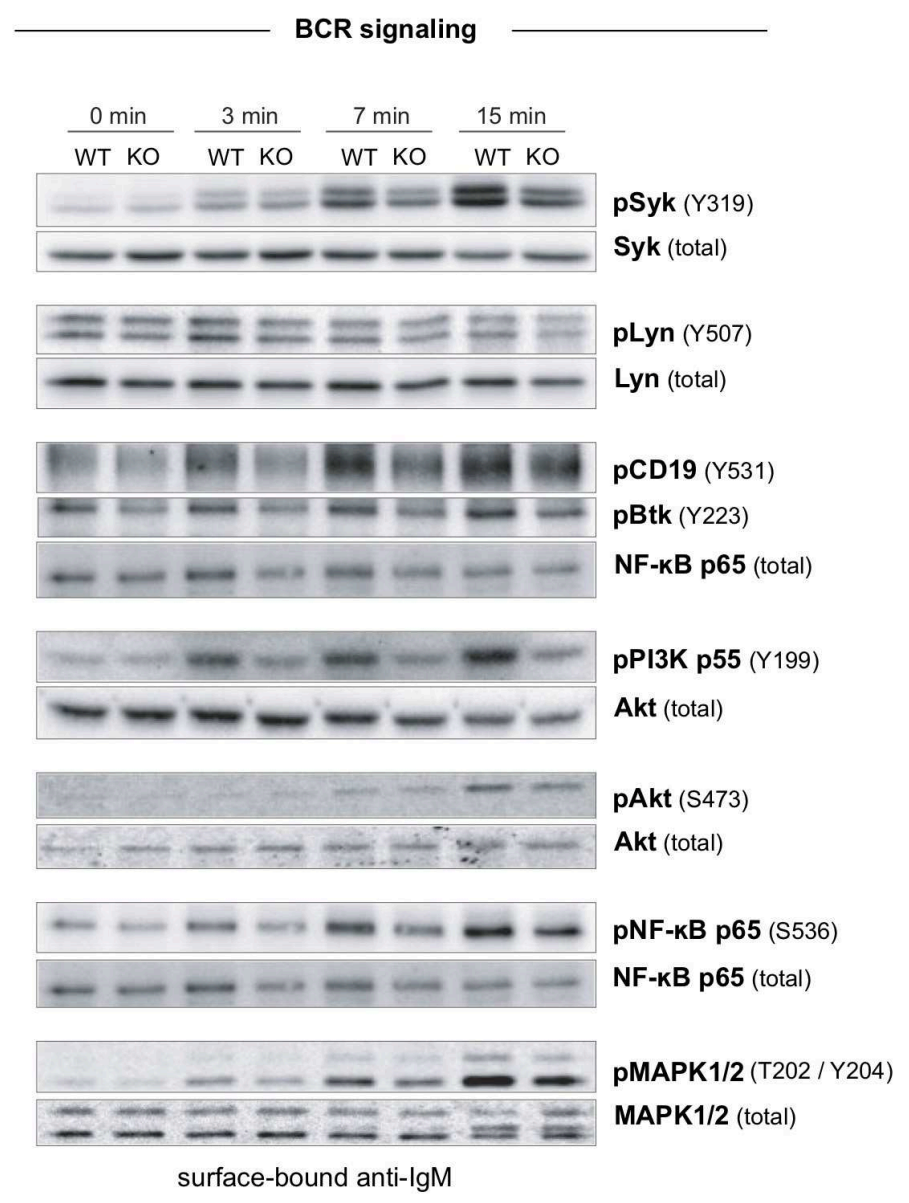

$\mathrm{Ca}^{2+}$ flux

$5 \mu \mathrm{g} / \mathrm{ml}$
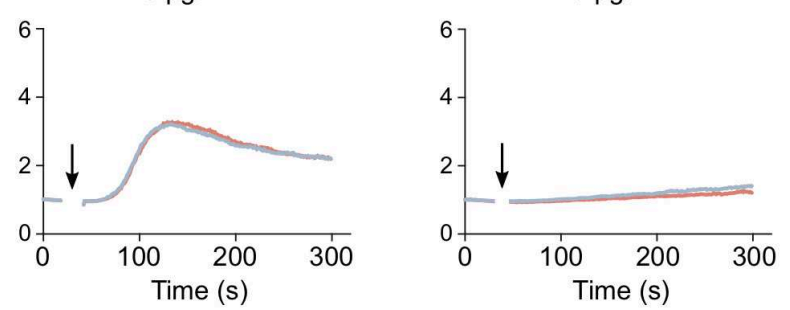

-WT - KO

$1 \mu \mathrm{g} / \mathrm{ml}$

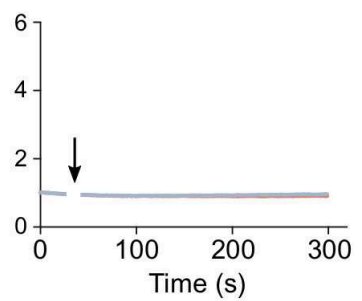

C
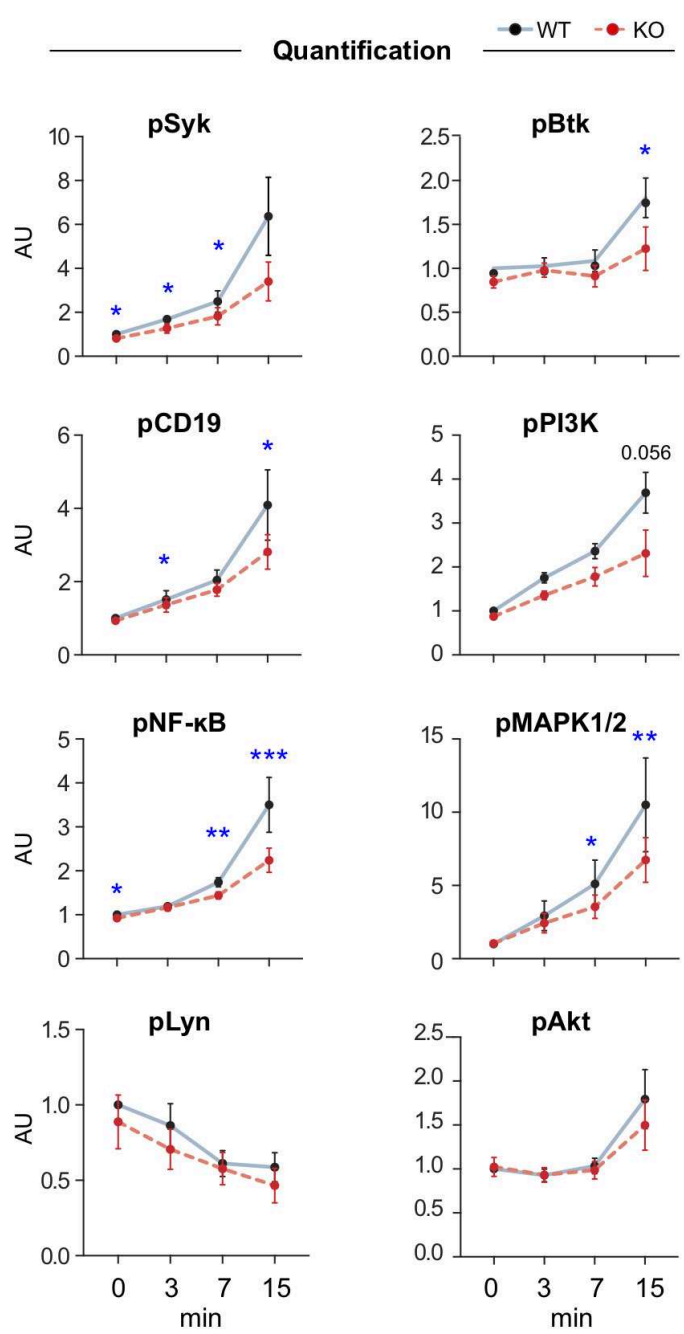

FIGURE 2 | MIM deficiency leads to impaired B cell receptor signaling in response to surface-bound antigen. (A) Flow cytometry analysis of Ca ${ }^{2+}$ mobilization in response to BCR stimulation in solution. Splenic B cells from WT or MIM-KO mice were labeled with Fluo-4 and Fura Red and stimulated with 10, 5, 2.5, or $1 \mu \mathrm{g} / \mathrm{ml}$ anti-IgM antibodies. Time of anti-IgM antibody addition is indicated by an arrow. Data are presented as a ratio of Fluo-4 to Fura Red median fluorescence intensity. Mean values of three to five independent experiments are shown. (B) Splenic B cells were stimulated on surfaces coated with $5 \mu \mathrm{g} / \mathrm{ml}$ anti-lgM antibodies for 0, 3, 7, and $15 \mathrm{~min}$ and lysed. Lysates were subjected for immunoblotting for phosphorylated forms of different BCR signaling effector proteins. Unphosphorylated forms of the corresponding proteins were used as loading control, except for pCD19, pBtk, and pPI3K, where NF-kB p65, Syk or Akt were used as loading controls. (C) Quantification of the data in (B). Data are presented as ratios of phosphorylated forms to total protein levels and normalized to the level of WT at 0 min. Data are from four to eight independent experiments. Mean \pm SEM is shown. ${ }^{*} p<0.05,{ }^{* *} p<0.01,{ }^{* \star} p<0.001$. 
changes in the overall morphology, we visualized them using scanning electron microscopy (SEM), either in resting state or after 10 min activation by surface-tethered anti-IgM, mimicking the formation of the immunological synapse. In SEM, the morphology of $\mathrm{MIM}^{-/-} \mathrm{B}$ cells appeared grossly similar to WT cells (Figure 3A). However, to perform another, more quantitative analysis, we turned to fluorescent microscopy. We activated B cells on anti-IgM-coated coverslips and analyzed the area of spreading using TIRF microscopy, an imaging method ideal for visualization of the cell membrane-coverslip interface. The analysis of the TIRF images revealed that $\mathrm{MIM}^{-/-} \mathrm{B}$ cells spread slightly but consistently less than their WT counterparts (Figure 3B). To measure overall phosphorylation at the contact region, we stained the cells with anti-phospho-Tyrosine (pTyr) antibodies. Mean fluorescence intensities of pTyr were also reduced in $\mathrm{MIM}^{-/-} \mathrm{B}$ cells. To investigate the impaired BCR signaling and its kinetics in more detail, we next activated the B cells on anti-IgM coated coverslips for different timepoints and stained them with anti-pBtk and anti-pSyk antibodies, as well as phalloidin. Quantification of the pBtk and pSyk in the contact plane showed significantly reduced levels of these signals, as well as levels of spreading, in $\mathrm{MIM}^{-/-}$cells through different time points (Figure 3C). The diminished area of spreading and kinase signaling detected by microscopy are well in line with our results from immunoblotting that also showed impaired BCR signaling. However, based on the SEM data and F-actin staining of the splenocytes, $\mathrm{MIM}^{-/-}$cells do not exhibit major morphological defects in their actin cytoskeleton (Figures 3A-C).

Recognition of surface-bound antigens in vivo can involve interaction of B cells with antigenic determinants on substrates of various physical properties. While stiff substrates can include bacterial cell wall components or extracellular matrix-linked antigens, perhaps more typical encounter occurs on the surface of antigen presenting cells, where antigens remain laterally mobile. To understand if $\mathrm{MIM}^{-/-} \mathrm{B}$ cells can initiate robust $\mathrm{BCR}$ signaling upon encounter with mobile antigens, we first settled Fluo-4-loaded WT and $\mathrm{MIM}^{-/-} \mathrm{B}$ cells on supported lipid bilayers (SLB), containing anti-kappa antibodies and ICAM1. Mobilization of $\mathrm{Ca}^{2+}$ was imaged for $5 \mathrm{~min}$ by spinning disk confocal microscopy and analyzed with the CalQuo ${ }^{2}$ software package for MATLAB (22). Analysis of median Fluo-4 intensity and proportions of $\mathrm{MIM}^{-/-} \mathrm{B}$ cells with single peak or oscillatory $\mathrm{Ca}^{2+}$ intensity profiles revealed no differences between MIM-KO and WT cells (Figure 3D). Next, we evaluated the ability of MIM-KO cells to spread and form immunological synapses on SLBs. We performed live-cell imaging of WT and MIM-KO cells and recorded interference reflection microscopy (IRM) images to detect the overall contact area of the cells, and fluorescent antigen signal to follow antigen gathering in the synapse (Figure 3E). The movies showed fast cell spreading, reaching maximum in 1-2 min, followed by slower contraction response coinciding with antigen accumulation to form the mature immunological synapse. We did not detect any differences in the kinetics of synapse formation in MIM-KO cells as compared to WT counterparts. Also, in the mature synapses, analyzed after $10 \mathrm{~min}$ of contact with the SLB, $\mathrm{MIM}^{-/}$- B cells accumulated normal amounts of antigen in the center of the synapse (Figure 3E). Thus, while MIM modulates BCR signaling and spreading responses upon antigen contact on stiff substrates, upon engagement of membrane-bound mobile antigens, the cells are able to engage and gather normal amounts of antigen to the center of the immunological synapse. On membranous surfaces, spreading and contraction response is complemented with dynamic fluctuations of F-actin-rich protrusions, making the regulation of the cytoskeletal structures distinct from spreading on immobilized antigens.

\section{MIM Is Required for an Efficient Antibody Response Against T-Independent Antigen}

To test if the defected signaling in $\mathrm{MIM}^{-/-} \mathrm{B}$ cells leads into problems in mounting of the immune responses, we went on to examine antibody levels of our mice first at the basal state and then upon immunization with $\mathrm{T}$ cell-independent (TI) or T celldependent (TD) model antigens. We saw no significant changes in the basal antibody levels in the sera of WT and $\mathrm{MIM}^{-/-}$mice (Figure 4A). To study the development of antibody responses toward TI antigens, we immunized mice with NP-FICOLL (Figures 4B-D). Throughout the examination time course of 28 days, we found reduced levels of both total and NP-specific IgM in $\mathrm{MIM}^{-/-}$mice (Figures 4C,D). Interestingly, we also detected impaired responses in the total levels of IgG subtypes, most profound in IgG2b, while the production of NP-specific IgG subclasses was not impaired (Figure 4D).

For immunizations with TD protein antigen, we used $\mathrm{NP}-\mathrm{KLH}$ in alum and followed up the primary response for 4 weeks. Four months later, we stimulated a memory response and followed that for 2 weeks (Supplementary Figure S4A). In contrast to TI immunization scheme, we found that $\mathrm{MIM}^{-/-}$mice were as efficient in mounting antibody responses to a protein antigen as their WT counterparts (Supplementary Figures S4B,C). Analysis of the memory responses also showed equal levels of NP-specific IgG for all subclasses (Supplementary Figure S3D). Furthermore, we analyzed affinity maturation by comparing binding to low and high densities of NP-epitopes in ELISA, and found no significant differences between WT and $\mathrm{MIM}^{-/-}$mice (Supplementary Figure S4E).

In the light of defects in BCR signaling and TI immune responses in $\mathrm{MIM}^{-/-}$mice, normal antigen-specific IgG immune responses may point toward compensation by other signals in the system, such as $\mathrm{T}$ cell help. To dissect the $\mathrm{B}$ cell intrinsic features linked to IgG antibody responses in more detail, we set up an in vitro assay for class-switch recombination (CSR). We provoked B cells to change the isotype of the produced Ig molecules, by mimicking cellular events of pathogen encounter or $\mathrm{T}$ cell help during maturation of IgG antibody responses. As expected, 3 days of $B$ cells activation with LPS or CD40L in combination with cytokines induced switching of surface-expressed Ig molecules to different IgG isotypes, as detected by flow cytometry. Consistent with the in vivo data on generation of NP-specific IgG antibody responses, $\mathrm{MIM}^{-/-}$ $\mathrm{B}$ cells switched normally in all tested conditions, producing similar percentages of $\mathrm{IgG}^{+}$cells, indicating that MIM is not 
A

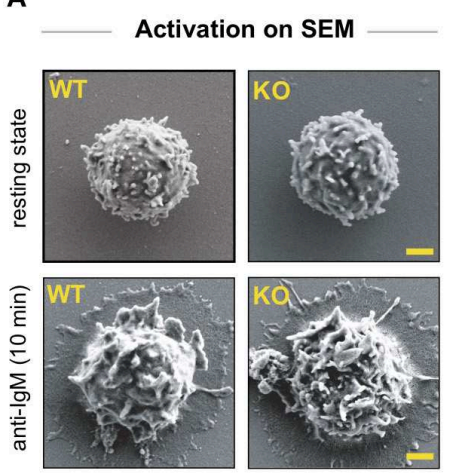

D
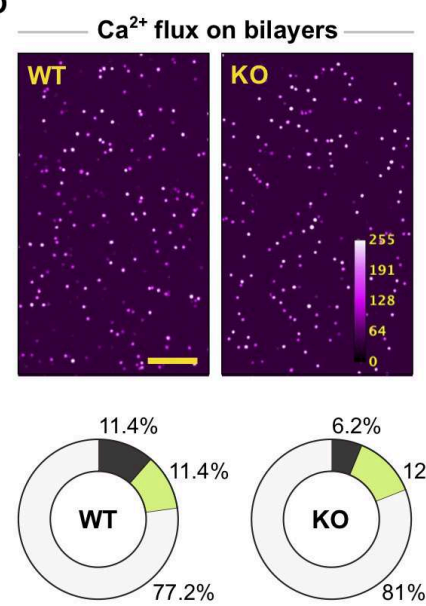

Non-triggering Single peak

Oscillatory$$
\text { (n) }
$$

B

Spreading on coverslips

OWT OKO
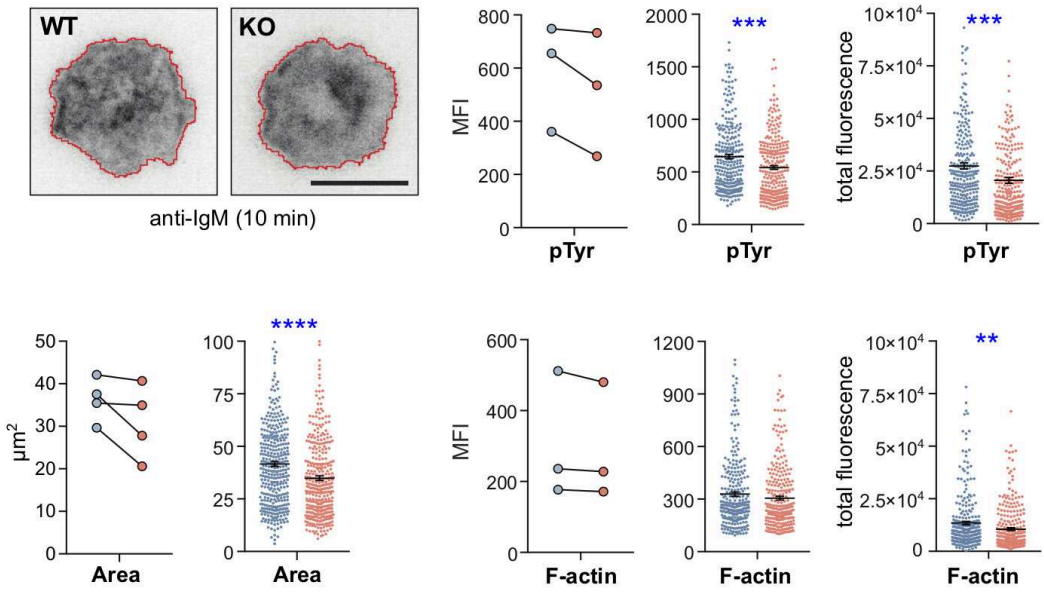

C

Signaling on coverslips

-WT $--K O$
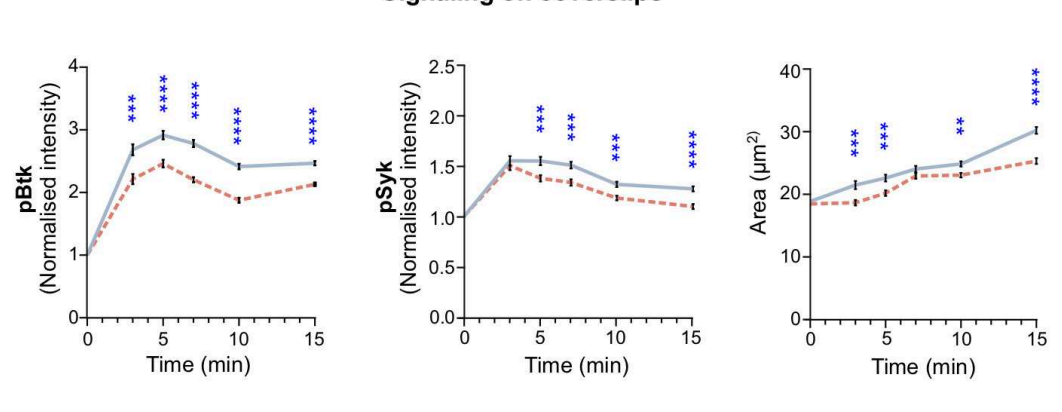

E

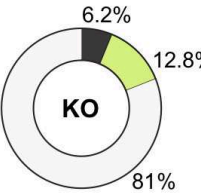

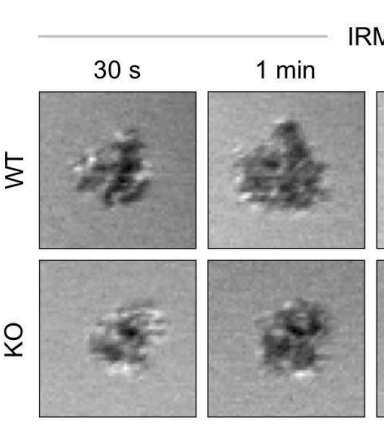

IRM

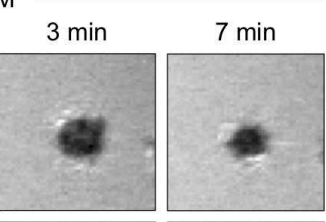

Activation on supported lipid bilayers

$\varpi \mathrm{WT}=\mathrm{KO}$
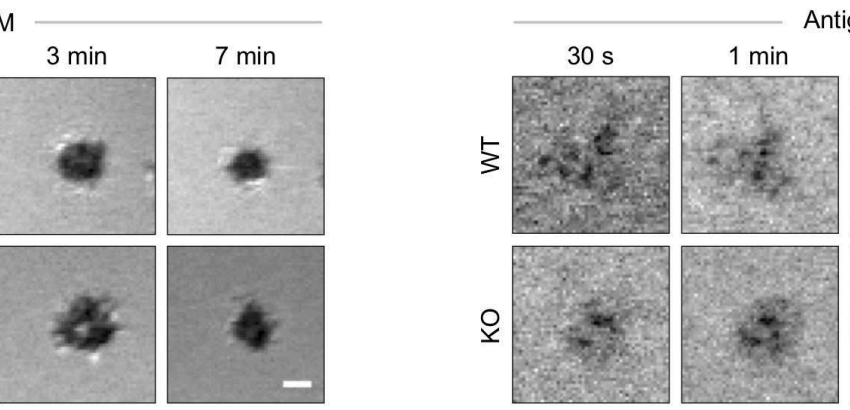

Antigen
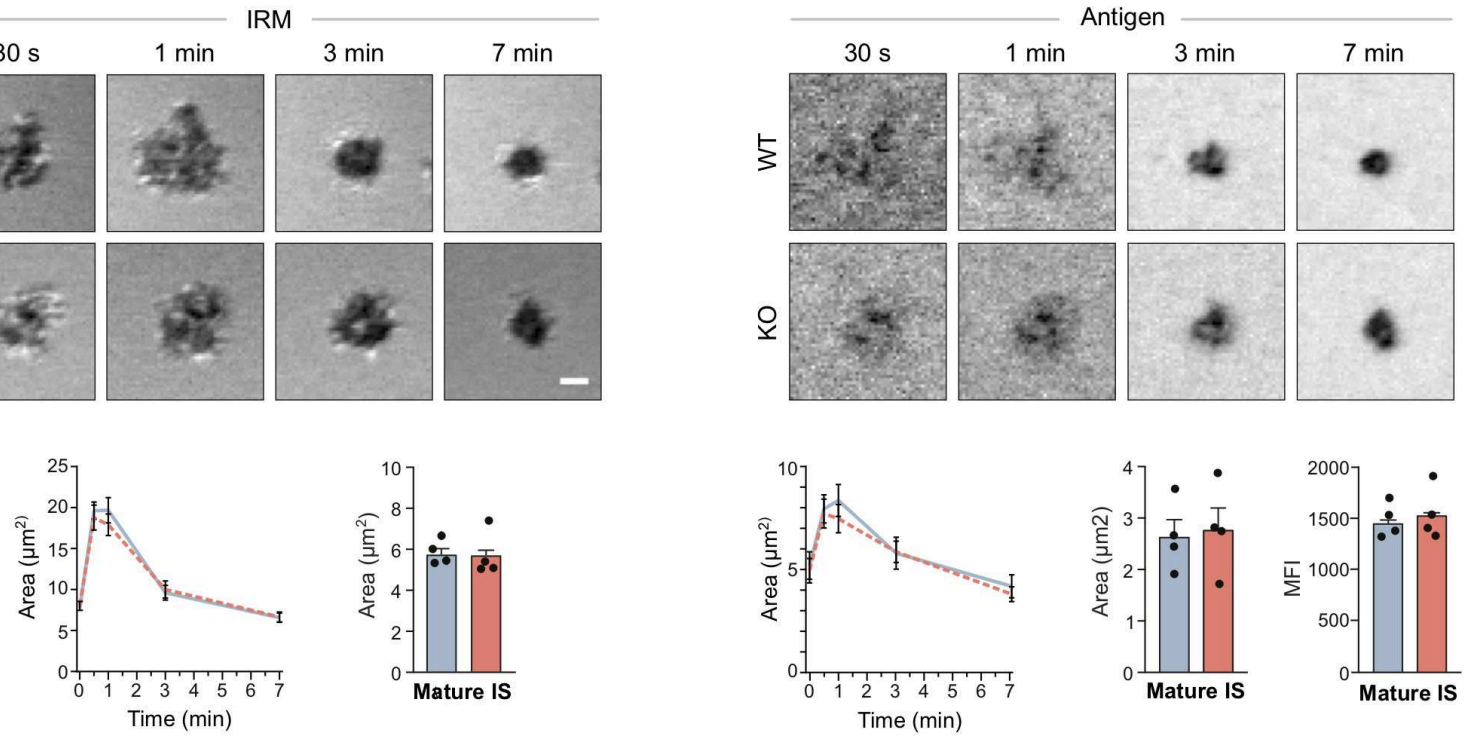

FIGURE 3 | MIM-/- B cells show diminished spreading and signaling on antigen-coated glass, but gather normal levels of antigen on supported lipid bilayers. (A) Scanning electron micrographs of WT and MIM-KO splenic B cells at resting state, let to adhere on CellTak-coated coverslips, or let to spread and get activated on 
FIGURE 3 | coverslips coated with $5 \mu \mathrm{g} / \mathrm{ml}$ anti-IgM for $10 \mathrm{~min}$. Scale bar, $1 \mu \mathrm{m}$. (B) Splenic B cells were stimulated on coverslips coated with $7.5 \mu \mathrm{g} / \mathrm{ml}$ anti-lgM antibodies for $10 \mathrm{~min}$, fixed, permeabilized, and stained with phalloidin (F-actin) and anti-phospho-Tyrosine antibodies (pTyr). Samples were imaged with TIRF microscopy. Representative images showing cell spreading and F-actin staining, are shown (upper left). Area of spreading was analyzed by signal thresholding in pTyr channel (lower left panels), and pTyr (upper right panels) and F-actin (lower right panels) intensities inside cell perimeter were quantified using Image J. Mean (MFI) and total (total) fluorescence intensities of pTyr and F-actin stainings are shown, and the mean fluorescence intensity is presented both as pairwise comparison of geometric means of individual experiments (on the left) and as scatter plots of random sampling of 92 cells from each of three to four individual experiments (middle). Mean \pm SEM is shown. Scale bar, $5 \mu \mathrm{m}$. (C) Splenic B cells were stimulated on coverslips coated with $5 \mu \mathrm{g} / \mathrm{ml}$ anti-lgM antibodies for 3, 5, 7, 10 , and 15 min, fixed, permeabilized, and stained with phalloidin (F-actin) and anti-phospho-Btk (pBtk) or anti-phospho-Syk (pSyk) antibodies. Samples were imaged with spinning disk confocal microscopy. Area of spreading was analyzed by signal thresholding in phalloidin channel, and pBtk or pSyk mean fluorescence intensities (MFI) inside cell perimeter were quantified using ImageJ and normalized to non-activated cells (time $0 \mathrm{~min}$ ). Normalized MFI of pBtk and pSyk, and spreading area based on F-actin are shown. Data are shown as mean \pm SEM of four independent experiments ( 25-150 cells per condition per experiment). WT and KO cells were compared using unpaired $t$-test. (D) Intracellular $\mathrm{Ca}^{2+}$-flux was analyzed in splenic WT and MIM-KO B cells loaded with Fluo-4 and stimulated with anti-kappa light chain antibodies tethered on supported lipid bilayers (SLB). A spinning disk confocal microscope was used to record the Fluo-4 intensity and the intracellular Ca ${ }^{2+}$ levels were quantified with Ca/Quo ${ }^{2}$ software. Representative images of stimulated B cells, $85 \mathrm{~s}$ after injection into the chamber, are shown (upper panel). Mean percentages of non-triggering cells and cells with single peak or oscillatory responses are shown (lower panel). Data of three independent experiments. Scale bar, $100 \mu \mathrm{m}$. (E) Splenic WT and MIM-KO B cells were stimulated with monobiotinylated anti-kappa light chain antibodies tethered via AF647-labeled streptavidin on SLBs. A laser scanning confocal microscope was used to detect IRM signal (panels on the left) corresponding to the area of contact and to measure the amount of antigen collected in the synapse from the AF647 signal (panels on the right). The data were quantified for cell area (graphs on the left), antigen area, and antigen fluorescence intensity (graphs on the right) during synapse formation ( $0-7 \mathrm{~min}$ ) by tracking individual cells from live cell imaging movies, and in the mature synapse (>10 min) by taking snapshots from several fields of views after movie acquisition. Data are from three to four independent experiments ( $\sim 25-30$ cells per condition in the movie, $\sim 400-450$ cells in the snapshots). Data were compared using unpaired $t$-test. Mean \pm SEM is shown. Scale bar, $1 \mu \mathrm{m} .{ }^{\star \star} p<0.01,{ }^{\star \star \star} p<0.001,{ }^{\star \star \star \star} p<0.0001$.

required for CSR in response to TLR ligands or CD40L and cytokines. In fact, switching rates into the most common isotypes were even slightly higher for $\mathrm{MIM}^{-/-} \mathrm{B}$ cells when stimulated with LPS (Supplementary Figures S5A-D). We also loaded the cells with Cell Trace Violet dye, which allowed us to analyze fluorescence profiles of dividing splenic B cells in response to these stimuli. We found robust proliferation of $\mathrm{MIM}^{-/-}$ B cells when they were activated with LPS, CD40L or antiIgM + CD40L (Supplementary Figure S5E). Analysis of the proliferation indices (PI) showed close to equal proliferation of MIM-KO and WT cells in all conditions tested. Notably, the division indices (DI) of $\mathrm{MIM}^{-/-}$B cells were moderately, but significantly, increased in CD40L + IFNg cultures, reflecting smaller numbers of cells left undivided, further indicating normal or even improved ability of $\mathrm{MIM}^{-/-}$cells to react to conditions similar to T cell help.

Our immunization studies suggest that MIM plays a role in IgM antibody responses to TI type 2 antigens, which haptenated FICOLL represents. However, MIM is dispensable for the development of antibodies against TD protein antigens. The ability to switch the antibody class upon polyclonal activation with LPS, TI type 1 antigen, appeared normal. Although by using a conventional MIM knockout mouse model we cannot rule out the influence of other immune and stromal cells on the immune responses generated in vivo, $\operatorname{IgM}$ antibody responses to TI antigens are considered to be largely B cell intrinsic and in the case of TI type 2 antigens rely primarily on intact BCR signaling. Thus, the defects in IgM antibody responses are in line with the diminished BCR signaling observed in vitro (Figures 2B,C, 3B,C).

\section{$\mathrm{MIM}^{-/-}$B Cells Show Higher Metabolic Profile Upon LPS and CpG Stimulation}

Our results suggest that MIM plays a role in antibody responses to TI-2 antigens. In vivo, however, T cell-independent antigens are usually associated with pathogenic determinants recognized by Toll-like receptors, important modulators of B cell immune responses (27). Activation of resting lymphocytes upon BCR engagement or recognition of microbial components triggers dramatic changes in their metabolism. Upregulated metabolic activity meets the increased energetic demands of activated cells and supports active proliferation and differentiation into antibody-secreting cells. We next analyzed the metabolic reprogramming potential of $\mathrm{MIM}^{-/-}$B cells upon activation via either BCR or TLRs, or combination of both. The rates of cellular oxygen consumption (oxygen consumption rate, OCR), an estimate of mitochondrial respiration, and extracellular acidification (extracellular acidification rate, ECAR), an estimate of glycolysis, were measured with a Mito Stress test in the Seahorse platform. In this assay, serial injections of oligomycin, Carbonyl cyanide-4-(trifluoromethoxy)phenylhydrazone (FCCP) and rotenone/antimycin A (Rot/AA) mixture, sequentially inhibit ATP production, collapse the proton gradient membrane potential and finally shut down mitochondrial respiration. This system allows measurement of the basal OCR, maximal and spare respiratory capacities, as well as determination of non-mitochondrial respiration.

First, we analyzed metabolic responses to individual stimulations with BCR ligands or TLR agonists. To this end, we activated WT and $\mathrm{MIM}^{-/-}$B cells with LPS, CpG or anti-IgM + IL-4 for $24 \mathrm{~h}$ or kept them largely resting with IL-4 alone (Figure 5A). Already samples treated with IL-4 alone showed a slight but significant increase in the maximal respiration in $\mathrm{MIM}^{-/-}$B cells. Notably, we observed a significant increase in the metabolic profile of $\mathrm{MIM}^{-/-}$cells as compared to WT counterparts upon activation with TLR4 and TLR9 ligands, LPS or CpG. Approximately $20 \%$ increase in the maximum respiration of $\mathrm{MIM}^{-/-}$cells was measured upon treatment with LPS or CpG. MIM $^{-/-}$cells also showed similar increase in the basal OCR levels and almost 2-fold upregulation for spare respiratory capacity upon $\mathrm{CpG}$ activation. In contrast to TLR stimulations, $24 \mathrm{~h}$ activation via BCR led to a slight diminution in basal respiration and no differences in maximum and spare respiration levels in $\mathrm{MIM}^{-/-}$cells. The preferred 


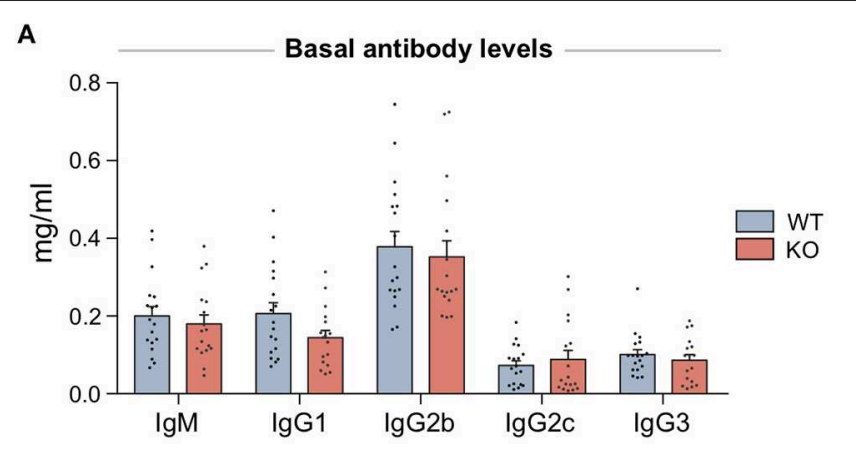

B

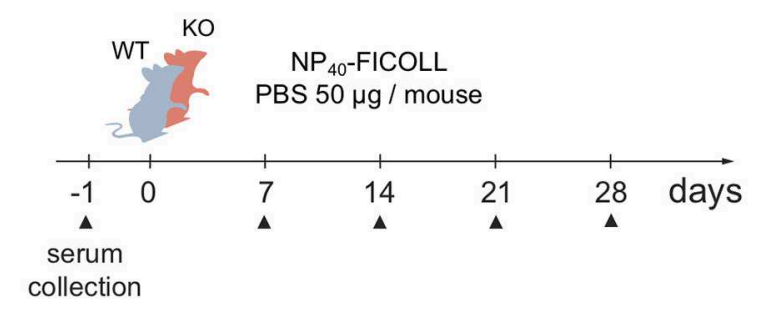

C
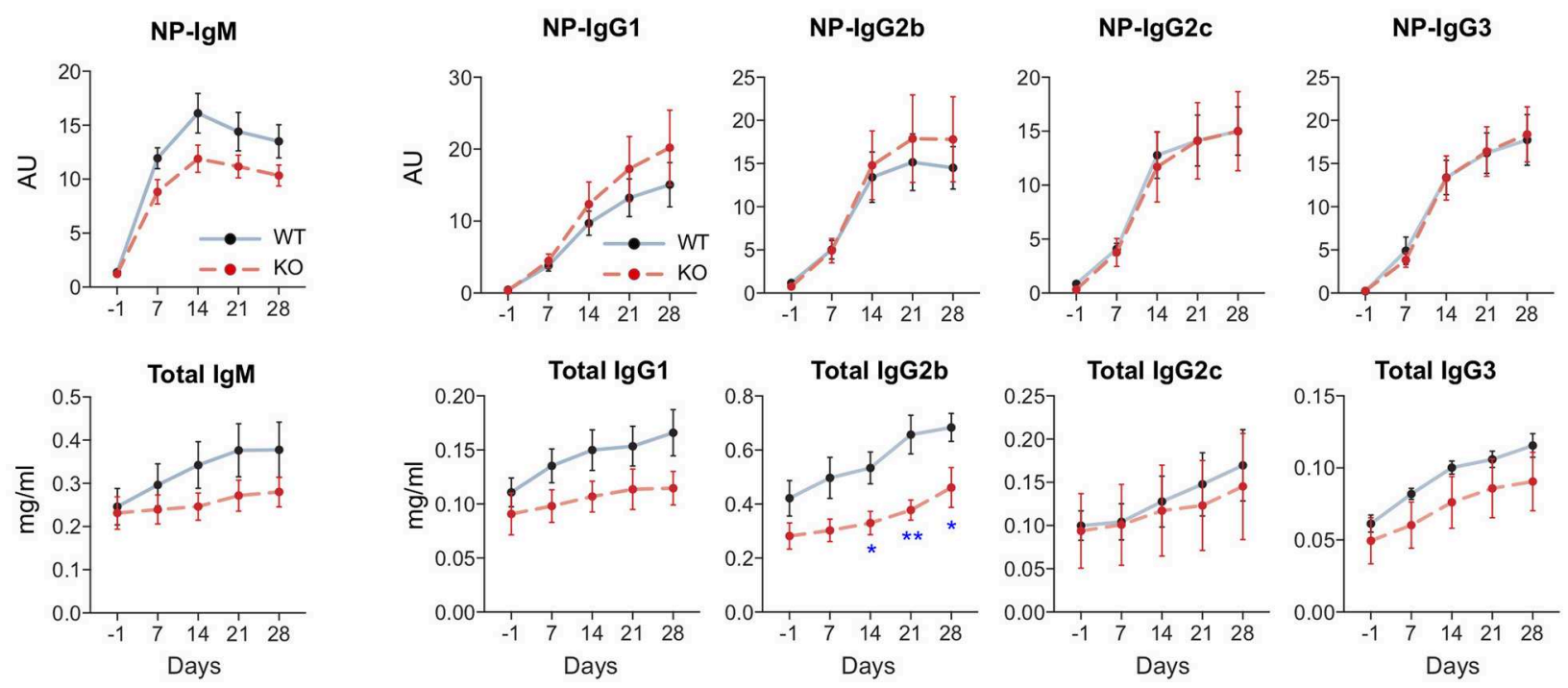

FIGURE 4 | MIM-deficiency results in impaired IgM response and reduced levels of total lgGs during T cell-independent immune response. (A) Basal antibody levels of major immunoglobulin subclasses were measured from 17 to $18 \mathrm{WT}$ and MIM KO mice. (B) A schematic representation of T cell-independent (TI) immunization study. (C,D) The antibody responses of immunized WT and MIM-KO mice were followed from serum samples as in (B). NP-specific and total antibody levels of (C) $\operatorname{lgM}$ and (D) IgG immunoglobulin isotypes were measured with ELISA. Seven to eight mice per group. Mean \pm SEM is shown. ${ }^{*} p<0.05,{ }^{* *} p<0.01$.

route of ATP generation, reflected by basal OCR to ECAR ratio, remained relatively constant across conditions, indicating no major shifts in the balance of oxidative phosphorylation and glycolytic metabolism.

To gain more understanding into the relationship of BCR and TLR signals in the activation of $\mathrm{MIM}^{-/-}$cells, we then asked how the metabolic reprogramming is affected by simultaneous engagement of BCR and TLR. To this end, we cultured WT and $\mathrm{MIM}^{-/-} \mathrm{B}$ cells for $24 \mathrm{~h}$ with a combination of antiIgM + LPS or anti-IgM + CpG and analyzed their metabolic profiles (Figure 5A). Surprisingly, we found that TLR-mediated increase in oxidative metabolism in $\mathrm{MIM}^{-/}$cells was restored to WT levels by simultaneous BCR engagement. To more directly compare these data to anti-IgM-stimulated cells, where IL-4 was added to increase survival of the cells, we carried out analysis of anti-IgM + LPS/CpG -stimulated cells also in the presence of IL-4. We found that simultaneous engagement of $\mathrm{BCR}$ also in these conditions reverted the TLR-mediated increase in oxidative metabolism in $\mathrm{MIM}^{-/-} \mathrm{B}$ cells closer to WT levels (Supplementary Figure S6A). However, the negative effect of anti-IgM was less efficient in the presence of IL-4, consistent with the finding that IL-4 supports metabolic reprograming toward higher oxidative state levels in $\mathrm{MIM}^{-/-}$cells.

Finally, we asked if the higher metabolic activity of $\mathrm{MIM}^{-/-}$ $\mathrm{B}$ cells reflects a bona fide change in the mitochondrial activity or is a result of elevated mitochondrial biogenesis upon TLRmediated metabolic reprograming. To this end, we stained mitochondria with TMRE and antibodies against Tom20 to assess mitochondrial membrane potential and mitochondrial mass, respectively. In freshly isolated splenic $\mathrm{MIM}^{-/-}$B cells, we found slightly but significantly elevated mitochondrial mass without significant increase in mitochondrial membrane potential (Figure 5B). As expected, activation of B cells with either anti-IgM + IL-4, LPS or CpG increased mitochondrial biogenesis and membrane potential, with $\mathrm{CpG}$ inducing most potent response (Figure 5C). However, WT and $\mathrm{MIM}^{-/-} \mathrm{B}$ cells 

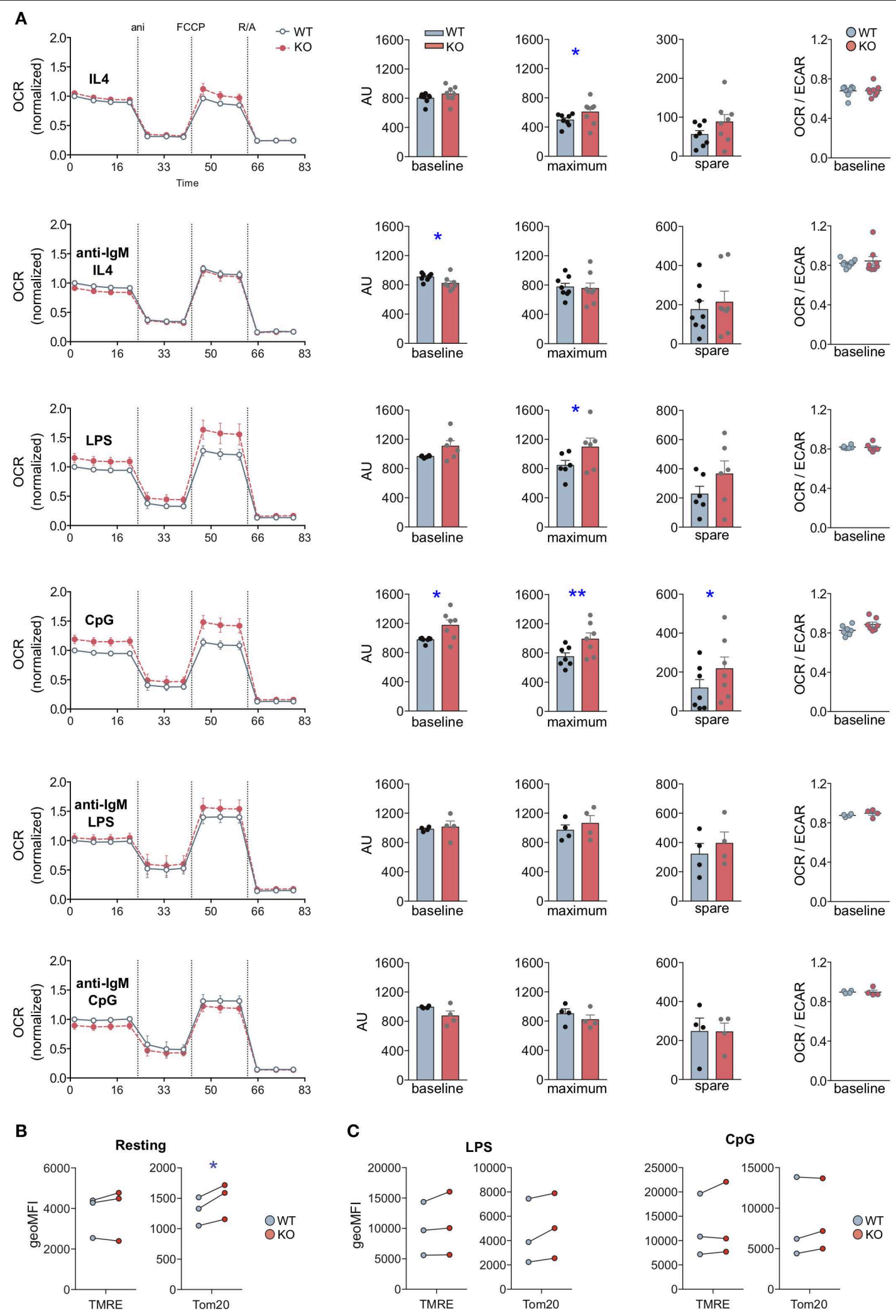

FIGURE 5 | MIM-deficient B cells show increased metabolic activity upon stimulation with Toll-like receptor ligands LPS and CpG. (A) Oxygen consumption rate (OCR) profiles of WT and MIM-KO splenic B cells stimulated with IL-4, anti-lgM + IL-4, LPS, CpG, anti-lgM + LPS, or anti-lgM + CpG for $24 \mathrm{~h}$ were measured in 
FIGURE 5 | a Seahorse XF Cell Mito Stress Test assay. The different steps of the assay are depicted in the graph on the left showing mean \pm SEM. Comparisons of baseline mitochondrial respiration as well as maximum and spare respiratory capacities, extracted from the assay, are shown in the graphs in the middle, and quantification of the ratio of OCR to extracellular acidification rate (ECAR) at the baseline is shown on the right. Data presented as mean of four to eight independent experiments. Mean \pm SEM. (B,C) Splenic B cells, either left unstimulated (B) or stimulated with LPS or CpG for $24 \mathrm{~h}$ (C), were loaded with TMRE to probe for the mitochondrial membrane potential, or stained with anti-Tom20 antibodies to derive total mitochondrial mass. The samples were analyzed by flow cytometry. Data of three independent experiments. Mean \pm SEM. ${ }^{*} p<0.05,{ }^{\star *} p<0.01$.

showed comparable levels of mitochondrial membrane potential as well as mitochondrial mass after TLR stimulation. This suggests that the changes we observed in the metabolic activity of $\mathrm{MIM}^{-/-}$cells occur without detectable additional mitochondrial biogenesis but are rather a function of increased efficiency that might not be adequately represented by TMRE. Functional changes in the mitochondrial and metabolic activity may also be reflected by cell size (28). We found that CpG- but not LPS- or anti-IgM + IL-4-activated $\mathrm{MIM}^{-/-}$cells often showed slightly increased forward scatter characteristics when analyzed by flow cytometry (Supplementary Figure S6B). Together, our results suggest that in response to TLR4, TLR9, or IL-4 stimulation, MIM negatively regulates metabolic reprograming of $\mathrm{B}$ cells, decreasing reserves of oxidative metabolism, which are accompanied by functional changes in the mitochondrial activity, rather than mitochondrial biogenesis. Interestingly, in $\mathrm{MIM}^{-/-}$ $B$ cells, simultaneous engagement of BCR reverts TLR-mediated increase in oxidative mitochondrial activity.

\section{DISCUSSION}

In this study, we examined the enigmatic cytoskeletonmembrane linker protein MIM in B cells, where it is strongly expressed and also implicated in B cell lymphomas (12). In our mouse model, we found diminished TI antibody responses, as well as defected BCR signaling, indicative of a role in B cell activation and mounting of humoral immune responses. Together with the upregulated metabolic boost and normal proliferative responses in $\mathrm{MIM}^{-/-} \mathrm{B}$ cells upon TLR activation, our data suggest a complex role for MIM in modulation of different signaling pathways and cell fitness.

The predisposition of another MIM knockout mouse strain to lymphomagenesis, reported by Zhan and colleagues, is intriguing (12). We found the spleens of $\mathrm{MIM}^{-/-}$mice at the age of 2-7 months normal in size and cellularity, but as we did not perform aging experiments, we cannot preclude problems later in life. Regarding B cell development, Zhan and colleagues at first showed aberrant levels of total $\mathrm{CD} 19^{+}$or $\mathrm{CD} 9^{+} \mathrm{IgM}^{+}$cells in lymphoid organs (12), yet later reported normal B cell numbers (13). Following the same gating strategy, the numbers of pre-B cells in our $\mathrm{MIM}^{-/}$strain appeared normal (Supplementary Figures S1B,C), and we postulate that the observed discrepancies may arise from differences in strain maintenance or mouse age at the time of immunophenotyping. The possible consequences of the deletion of MIM for B cell development might also be too subtle to manifest in all models. In our model, we, however, noted mildly elevated numbers of MZ B cells in the spleens of $\mathrm{MIM}^{-/-}$mice (Figure 1F). The mouse strain generated by Zhan and colleagues used embryonic stem (ES) cells with insertion of gene trap sequence between exons 3 and 4 (clone CSC156, BayGenomics) (29). Notably, an independent attempt to recapitulate the generation of $\mathrm{MIM}^{-/-}$ strain with the same clone of ES cells resulted in an inefficient use of delivered splicing acceptor site (30). This left a considerable expression of full-length Mtss1 at both mRNA and protein levels, and variable remaining expression levels between animals, indicative of lability of the splicing. Lack of MIM expression in analyzed cells was, however, shown by Zhan and colleagues $(12,29)$. In our strain, where a neomycin cassette with several stop codons is inserted in exon 1 of $M t s s 1$, low levels of alternative splicing have been previously observed. However, the generated transcript translates into an N-terminally truncated polypeptide chain, where the critical I-BAR domain is functionally inhibited, and which did not yield detectable levels of protein expression (18). In this study, confirmative of the lack of MIM expression in B cells, we also confirmed a clear and repeatable loss of detectable protein expression in our substrain, using two different commercial antibodies (Figure 1A).

$\mathrm{MIM}^{-/-}$B cells exhibited consistently diminished phosphorylation of several BCR effector molecules upon stimulation of BCR with surface-bound antigen (Figures 2B,C). This defect was in line with smaller area of spreading and reduced overall tyrosine phosphorylation detected by microscopy at the site of contact with antigen (Figures 3B,C). Although lower amount of engaged antigen due to inefficient actin-dependent spreading response may partially contribute to the signaling defects observed in $\mathrm{MIM}^{-/-}$B cells, defected BCR signaling also leads to diminished spreading, generating a feedback loop. Signaling upon soluble antigen stimulation, on the other hand, was mostly normal, showing only slight diminution in the levels of pSyk (Supplementary Figures S3B,C). This suggests that MIM participates in the ability of $B$ cells to discriminate between different types of antigens by playing a specific role in B cell activation on surfaces. Although the differential responses of B cells to different forms of antigen are nowadays widely accepted $(1,26,31)$, to our knowledge, there are only few molecules, such as $\mathrm{CD} 19$ and $\mathrm{CD} 81(4,32)$, that have been reported to specifically regulate stimulation by surface-linked antigens with mechanisms likely separate from structural roles in cell adhesion or spreading. We also found that while stimulation with surface-bound antigen resulted to a certain degree in reduced phosphorylation of all the tested BCR effectors, the defects in proximal BCR signaling, exemplified by reduced pSyk and pCD19, did not propagate evenly downstream. Reduced pCD19 seemed to largely spare PI3K pathway (33) as pAkt levels are on par with those of WT (Figures 2B,C). At the same time, levels of both pNF- $\kappa \mathrm{B}$ and pMAPK1/2 were significantly reduced, suggesting defected DAG-PKC signaling module $(25,34,35)$. PKC-FAK axis has been implicated in the regulation of force-dependent $\mathrm{B}$ cell activation (36) and could be involved in the specific defects in 
response to surface-bound antigens that we observed. Regarding the previously suggested role for MIM in DLBCL (12), it is worth noting that dysregulated BCR signaling also plays a role in lymphomagenesis (37).

Our experiments on supported lipid bilayers (SLB) suggested that $\mathrm{MIM}^{-/-} \mathrm{B}$ cells are able to form signaling-competent BCR-antigen microclusters and gather normal amounts of antigen in the center of the immunological synapse (Figure 3E). Therefore, in this model system, coupling of BCR to actin and microtubule cytoskeleton, required for the cell spreading and antigen gathering, respectively, is not notably defected $(38,39)$. However, results from the laterally fluid SLBs, cannot be directly compared to B cell stimulation by immobilized antigens. SLBs are also not fully comparable to situations where the cells need to overcome frictional coupling of antigen-presenting molecules to the membrane skeleton of the APC (40-42). In addition, SLBs in our experiments were functionalized with ICAM-1, which is known to lower the threshold for B cell activation (21).

$\mathrm{MIM}^{-/-}$mice developed impaired IgM antibody responses to NP-FICOLL, but normal responses to NP-KLH immunization, indicating that the defects were specific to the nature of the encountered antigen. FICOLL polysaccharide haptenated with $\mathrm{NP}$ is a typical TI type 2 antigen, to which the response is thought to rely mainly on marginal zone B cells and peritoneal cavity B1b cells (43-46). As $\mathrm{MIM}^{-/-}$mice showed normal proportions of peritoneal and even elevated MZ B cell compartments (Figures 1F,G), inadequate numbers of these B cell populations are unlikely to be responsible for the reduced anti-NP IgM levels (Figure 4C). However, further studies will be required to assess the functionality of B1 and MZ B cells in more detail. We consider the defects in possible indirect $\mathrm{T}$ cell help unlikely, due to the low expression of MIM in T cells (12), normal $\mathrm{CD}^{+} \mathrm{T}$ cell numbers (Figure 1E), intact antibody responses to TD antigen NP-KLH (Supplementary Figure S4), as well as comparable levels of class-switched IgG antibodies in response to NP-FICOLL immunization (Supplementary Figure S5). We suggest that the impaired NP-FICOLL responses in $\mathrm{MIM}^{-/-}$ mice are caused by defected BCR-mediated signaling, induced by cell surface-associated FICOLL molecules. This would be in line with the prevailing idea that in vivo $\mathrm{B}$ cells recognize and respond to antigens that are immobilized on the surface of other cells in the secondary lymphoid organs (47). In case of NP-KLH stimulation, these defects could be rescued by second signals, to which, based on our data, $\mathrm{MIM}^{-/-}$cells respond well (Figure 5 and Supplementary Figures S5, S6).

While naive, resting B cells have a considerably low metabolic profile, they elevate their metabolic rates upon activation, which is typically manifested by an increase in oxygen consumption and glycolysis (48-51). The mitogenic stimuli IgM, LPS, and CpG have been shown to dramatically increase metabolic requirements of $\mathrm{B}$ cells, playing a key role in this transition, essential for differentiation into antibody secreting cells and productive immune responses $(50,52)$.

Our results suggest that MIM plays a negative role in metabolic reprogramming of B cells toward oxidative metabolic activity upon TLR4 and especially TLR9 engagement as we found that MIM $^{-/-}$B cells exhibited $\sim 20 \%$ increased metabolic activity after stimulation with either LPS or CpG, respective agonists for TLR4 and TLR9 (Figure 5). In contrast, basal OCR levels upon activation with anti-IgM + IL-4 were reduced in $\mathrm{MIM}^{-/-}$ cells reflecting impaired BCR signaling observed in these cells. It is possible that STAT6 signaling triggered by IL-4 present in culture to increase the survival of the cells dilutes the effects of defected anti-IgM signaling in $\mathrm{MIM}^{-/-}$cells and leads to underestimate of the difference, as IL-4 alone leads to increased metabolic activity in $\mathrm{MIM}^{-/-}$cells.

How exactly the impaired BCR signaling and abnormal metabolic rewiring of $\mathrm{MIM}^{-/-} \mathrm{B}$ cells in response to TLR engagement can be explained together is an intriguing question. Surprisingly, addition of BCR engagement at the same time with TLR agonists was found to negate the metabolic phenotype found in $\mathrm{MIM}^{-/-} \mathrm{B}$ cells treated with TLR agonists alone. This suggests that increased metabolic capacity in $\mathrm{MIM}^{-/-}$cells could compensate for the effects of compromised BCR signaling upon in vivo B cell activation and differentiation. However, how the different combinations of ligands are sensed by both BCR and TLRs presents complex and largely unresolved issues. In addition to distinct modes of BCR signaling induced by soluble or surface-tethered ligands, responses to simultaneous but unlinked BCR + TLR stimulations are qualitatively different from co-engagement of BCR and TLR by cross-linked ligands $(53,54)$. Thus, the exact mechanism of how MIM affects oxidative metabolic activity in response to TLR-mediated reprograming remains to be further investigated. There is, however, a large body of evidence showing that in B cells, TLR4/9-mediated responses are dependent on BCR signaling components, including BCR itself (53-60). Yet, although MIM $^{-/-}$cells were defected in activation of CD19, PI3K, Syk, Btk, NF-kB, and MAPK1/2 phosphorylation upon antigenic activation, we observed no abnormalities in proliferation of $\mathrm{MIM}^{-/-} \mathrm{B}$ cells in response to either LPS or CpG (Supplementary Figure S5E and data not shown). In the case of CpG, defects in Dock8-Src-Syk-STAT3 (56) and PI3K/Akt-GSK3b-Foxo1 (57) axes primarily manifest as problems in proliferation. Inhibition of these modules, as well as MyD88-Pyk2-Lyn and CD19-PI3K-Akt (58), in CpG-activated cells, however, leaves activation of NF- $\kappa B$ and MAPK1/2 largely intact. Thus, NF- $\kappa \mathrm{B}$ and MAPK1/2 possess, at least partially, independent roles in TLR9 activation and may be responsible for the metabolic changes seen in CpG-activated $\mathrm{MIM}^{-/-} \mathrm{B}$ cells. Indeed, NF- $\kappa B$ has been shown to reduce mitochondrial oxidative metabolism in sarcoma cells and MAPK1/2 have been shown to promote glycolytic shift in some cancer types, as well as in rapidly proliferating cells $(61,62)$. This suggests that impaired activation of these modules may underpin the elevated oxidative metabolism in $\mathrm{MIM}^{-/-}$B cells. Supporting the complex relationship of metabolism with BCR and other activatory signals, it has been found that while BCR signaling initially leads to enhanced mitochondrial function, this response also rapidly shifts toward mitochondrial dysfunction if not rescued with second signals such as TLR9 agonists (49). Akkaya and colleagues did not study the effects of IL-4 in this context, but it seems plausible that similar rescue of the BCR-induced mitochondrial dysfunction also takes places upon IL-4 treatment. Interestingly, it has also been found that although many B 
cell lymphomas depend on intact tonic or antigen-driven BCR signaling, a subset of diffuse large B cell lymphomas (DLBCL), called OxPhos DLBCL, with gene expression signature enriched in oxidative phosphorylation genes, does not express functional BCR $(63,64)$, pointing toward separation of these signal pathways. It remains to be seen if differential expression of MIM in different cancers, including lymphomas, may correlate with changes in the metabolic activity of the cancer cells.

\section{DATA AVAILABILITY STATEMENT}

All datasets generated for this study are included in the article/Supplementary Material and raw data will be provided upon request.

\section{ETHICS STATEMENT}

The animal study was reviewed and approved by Hankelupalautakunta (ELLA), Etelä-Suomen aluehallintovirasto (ESAVI).

\section{AUTHOR CONTRIBUTIONS}

AS and PM designed the study. AS, PP, SH-P, VŠ, EK, RS, MV, and LC designed and performed the experiments. AS, PP, SH-P, LC, MF, YC, and PM analyzed the data. PM, YC, and MF carried out supervision and provided resources for the project. AS and $\mathrm{PM}$ were in charge of writing the manuscript. Additionally, PP, $\mathrm{SH}-\mathrm{P}, \mathrm{LC}, \mathrm{MF}$, and YC contributed to the text.

\section{FUNDING}

This work was supported by the Academy of Finland (grant ID: $25700,296684,307313$, and 327378 to PM; 286712 to

\section{REFERENCES}

1. Mattila PK, Batista FD, Treanor B. Dynamics of the actin cytoskeleton mediates receptor cross talk: an emerging concept in tuning receptor signaling. J Cell Biol. (2016) 212:267-80. doi: 10.1083/jcb.201504137

2. Kuokkanen E, Šuštar V, Mattila PK. Molecular control of B cell activation and immunological synapse formation. Traffic. (2015) 16:311-26. doi: $10.1111 /$ tra. 12257

3. Treanor B, Depoil D, Gonzalez-Granja A, Barral P, Weber M, Dushek $\mathrm{O}$, et al. The membrane skeleton controls diffusion dynamics and signaling through the B cell receptor. Immunity. (2010) 32:187-99. doi: 10.1016/j.immuni.2009.12.005

4. Mattila PK, Feest C, Depoil D, Treanor B, Montaner B, Otipoby KL, et al. The actin and tetraspanin networks organize receptor nanoclusters to regulate B cell receptor-mediated signaling. Immunity. (2013) 38:461-74. doi: 10.1016/j.immuni.2012.11.019

5. Bosticardo M, Marangoni F, Aiuti A, Villa A, Grazia Roncarolo M. Recent advances in understanding the pathophysiology of Wiskott-Aldrich syndrome. Blood. (2009) 113:6288-95. doi: 10.1182/blood-2008-12-115253

6. Mattila PK, Salminen M, Yamashiro T, Lappalainen P. Mouse MIM, a tissue-specific regulator of cytoskeletal dynamics, interacts with ATP-actin monomers through its C-terminal WH2 domain. J Biol Chem. (2003) 278:8452-9. doi: 10.1074/jbc.M212113200
VŠ), Sigrid Juselius and Jane and Aatos Erkko foundations (to PM), Turku doctoral program in molecular medicine (TuDMM) (to SH-P and MV), and Magnus Ehrnrooth (to AS) and Finnish Cultural (to VŠ) foundations. MF and LC were supported by the Wellcome Trust $(212343 / \mathrm{Z} / 18 / \mathrm{Z})$ and EPSRC (EP/S004459/1).

\section{ACKNOWLEDGMENTS}

We are thankful to Laura Grönfors for technical assistance, Elmeri Kiviluoto for assistance in image analysis, Dr. Maria Georgiadou and Prof. Johanna Ivaska for their help and generosity with Seahorse assays, as well as Dr. Diana Toivola and Joel Nyström for their help and generosity regarding the reagents for studying mitochondria. Central Animal Laboratory of University of Turku is acknowledged for good care of the mice. We thank Tero Vahlberg from the Biostatistics unit, University of Turku, for his advice on statistical analysis. We thank Laboratory of Electron Microscopy at the Institute of Biomedicine, University of Turku. Microscopy and flow cytometry were performed at the Turku Bioscience Cell Imaging and Cytometry core facility, supported by Turku Bioimaging and Euro-Bioimaging consortiums. We thank the personnel for their generous help and expertise. Biocenter Finland is acknowledged for providing the research infrastructures, particularly for cell imaging and cytometry, and electron microscopy. This manuscript has been released as a Pre-Print at BioRxiv (65).

\section{SUPPLEMENTARY MATERIAL}

The Supplementary Material for this article can be found online at: https://www.frontiersin.org/articles/10.3389/fimmu. 2020.00599/full\#supplementary-material

7. Mattila PK, Pykäläinen A, Saarikangas J, Paavilainen VO, Vihinen H, Jokitalo E, et al. Missing-in-metastasis and IRSp53 deform PI(4,5)P2-rich membranes by an inverse BAR domain-like mechanism. J Cell Biol. (2007) 176:953-64. doi: $10.1083 /$ jcb. 200609176

8. Safari F, Suetsugu S. The BAR domain superfamily proteins from subcellular structures to human diseases. Membranes. (2012) 2:91-117. doi: 10.3390/membranes2010091

9. Woodings JA, Sharp SJ, Machesky LM. MIM-B, a putative metastasis suppressor protein, binds to actin and to protein tyrosine phosphatase delta. Biochem J. (2003) 371:463-71. doi: 10.1042/bj20021962

10. Lin J, Liu J, Wang Y, Zhu J, Zhou K, Smith N, et al. Differential regulation of cortactin and N-WASP-mediated actin polymerization by missing in metastasis (MIM) protein. Oncogene. (2005) 24:2059-66. doi: $10.1038 /$ sj.onc. 1208412

11. Cao M, Zhan T, Ji M, Zhan X. Dimerization is necessary for MIM-mediated membrane deformation and endocytosis. Biochem J. (2012) 446:469-75. doi: 10.1042/BJ20120329

12. Yu D, Zhan XH, Zhao XF, Williams MS, Carey GB, Smith E, et al. Mice deficient in MIM expression are predisposed to lymphomagenesis. Oncogene. (2012) 31:3561-8. doi: 10.1038/onc.2011.509

13. Zhan T, Cao C, Li L, Gu N, Civin CI, Zhan X. MIM regulates the trafficking of bone marrow cells via modulating surface expression of CXCR4. Leukemia. (2016) 30:1327-34. doi: 10.1038/leu.2016.39 
14. Li L, Baxter SS, Gu N, Ji M, Zhan X. Missing-in-metastasis protein downregulates CXCR4 by promoting ubiquitylation and interaction with small Rab GTPases. J Cell Sci. (2017) 130:1475-85. doi: 10.1242/jcs.198937

15. Zhao P, Chen B, Li L, Wu H, Li Y, Shaneen B, et al. Missing-in-metastasis protein promotes internalization of magnetic nanoparticles via association with clathrin light chain and Rab7. Biochim Biophys Acta Gen Subj. (2019) 1863:502-10. doi: 10.1016/j.bbagen.2018.12.002

16. Machesky LM, Johnston SA. MIM: a multifunctional scaffold protein. J Mol Med. (2007) 85:569-76. doi: 10.1007/s00109-007-0207-0

17. Petrov P, Sarapulov AV, Eöry L, Scielzo C, Scarfò L, Smith J, et al. Computational analysis of the evolutionarily conserved missing in metastasis/metastasis suppressor 1 gene predicts novel interactions, regulatory regions and transcriptional control. Sci Rep. (2019) 9:4155. doi: 10.1038/s41598-019-40697-1

18. Saarikangas J, Mattila PK, Varjosalo M, Bovellan M, Hakanen J, CalzadaWack J, et al. Missing-in-metastasis MIM/MTSS1 promotes actin assembly at intercellular junctions and is required for integrity of kidney epithelia. J Cell Sci. (2011) 124:1245-55. doi: 10.1242/jcs.082610

19. Saarikangas J, Kourdougli N, Senju Y, Chazal G, Segerstråle M, Minkeviciene $\mathrm{R}$, et al. MIM-induced membrane bending promotes dendritic spine initiation. Dev Cell. (2015) 33:644-59. doi: 10.1016/j.devcel.2015.04.014

20. Grakoui A, Bromley SK, Sumen C, Davis MM, Shaw AS, Allen PM, et al. The immunological synapse: a molecular machine controlling $\mathrm{T}$ cell activation. Science. (1999) 285:221-7. doi: 10.1126/science.285.5425.221

21. Carrasco YR, Fleire SJ, Cameron T, Dustin ML, Batista FD. LFA-1/ICAM1 interaction lowers the threshold of $\mathrm{B}$ cell activation by facilitating B cell adhesion and synapse formation. Immunity. (2004) 20:589-99. doi: 10.1016/S1074-7613(04)00105-0

22. Lee AM, Colin-York H, Fritzsche M. CalQuo 2 : Automated Fourier-space, population-level quantification of global intracellular calcium responses. Sci Rep. (2017) 7:1-11. doi: 10.1038/s41598-017-05322-z

23. Lee SH, Kerff F, Chereau D, Ferron F, Klug A, Dominguez R. Structural basis for the actin-binding function of missing-in-metastasis. Structure. (2007) 15:145-55. doi: 10.1016/j.str.2006.12.005

24. Harwood NE, Batista FD. Early events in B cell activation. Annu Rev Immunol. (2010) 28:185-210. doi: 10.1146/annurev-immunol-030409-1 01216

25. Mérida I, Carrasco S, Avila-Flores A. Diacylglycerol signaling: the C1 domain, generation of DAG, and termination of signals. In: Kazanietz MG, editor. Protein Kinase $C$ in Cancer Signaling and Therapy. Totowa, NJ: Humana Press (2010). p. 55-78. doi: 10.1007/978-1-60761-543-9

26. Bolger-Munro M, Choi K, Scurll JM, Abraham L, Chappell RS, Sheen D, et al. Arp2/3 complex-driven spatial patterning of the BCR enhances immune synapse formation, BCR signaling and cell activation. Elife. (2019) 8:e44574. doi: 10.7554/eLife.44574.045

27. Bekeredjian-Ding I, Jego G. Toll-like receptors - sentries in the B-cell response. Immunology. (2009) 128:311-23. doi: 10.1111/j.1365-2567.2009.03173.x

28. Miettinen TP, Björklund M. Mitochondrial function and cell size: an allometric relationship. Trends Cell Biol. (2017) 27:393-402. doi: 10.1016/j.tcb.2017.02.006

29. Yu D, Zhan XH, Niu S, Mikhailenko I, Strickland DK, Zhu J, et al. Murine missing in metastasis (MIM) mediates cell polarity and regulates the motility response to growth factors. PLoS ONE. (2011) 6:e20845. doi: 10.1371/journal.pone.0020845

30. Fahrenkamp D, Herrmann O, Koschmieder S, Brümmendorf TH, Schemionek M. Mtss1(CSC156) mutant mice fail to display efficient Mtss1 protein depletion. Leukemia. (2017) 31:1017-9. doi: 10.1038/leu.2017.19

31. Snapper CM. Distinct immunologic properties of soluble versus particulate antigens. Front Immunol. (2018) 9:598. doi: 10.3389/fimmu.2018.00598

32. Depoil D, Fleire S, Treanor BL, Weber M, Harwood NE, Marchbank KL, et al. CD19 is essential for B cell activation by promoting B cell receptorantigen microcluster formation in response to membrane-bound ligand. Nat Immunol. (2008) 9:63-72. doi: 10.1038/ni1547

33. Otero DC, Omori SA, Rickert RC. CD19-dependent activation of Akt kinase in B-lymphocytes. J Biol Chem. (2001) 276:1474-8. doi: 10.1074/jbc.M003918200
34. Su TT, Guo B, Kawakami Y, Sommer K, Chae K, Humphries LA, et al. PKC- $\beta$ controls IКB kinase lipid raft recruitment and activation in response to BCR signaling. Nat Immunol. (2002) 3:780-6. doi: 10.1038/ni823

35. Coughlin JJ, Stang SL, Dower NA, Stone JC. RasGRP1 and RasGRP3 regulate B cell proliferation by facilitating B cell receptor-Ras signaling. J Immunol. (2005) 175:7179-84. doi: 10.4049/jimmunol.175.11.7179

36. Shaheen S, Wan Z, Li Z, Chau A, Li X, Zhang S, et al. Substrate stiffness governs the initiation of $\mathrm{B}$ cell activation by the concerted signaling of $\mathrm{PKC} \beta$ and focal adhesion kinase. eLife. (2017) 6:e23060. doi: 10.7554/eLife.23060

37. Young RM, Staudt LM. Targeting pathological B cell receptor signalling in lymphoid malignancies. Nat Rev Drug Discov. (2013) 12:229-43. doi: $10.1038 / \mathrm{nrd} 3937$

38. Schnyder T, Castello A, Feest C, Harwood NE, Oellerich T, Urlaub H, et al. $\mathrm{B}$ cell receptor-mediated antigen gathering requires ubiquitin ligase $\mathrm{Cbl}$ and adaptors Grb2 and Dok-3 to recruit dynein to the signaling microcluster. Immunity. (2011) 34:905-18. doi: 10.1016/j.immuni.2011.06.001

39. Liu C, Miller H, Orlowski G, Hang H, Upadhyaya A, Song W. Actin reorganization is required for the formation of polarized B cell receptor signalosomes in response to both soluble and membrane-associated antigens. J Immunol. (2012) 188:3237-46. doi: 10.4049/jimmunol.1103065

40. Ketchum C, Miller H, Song W, Upadhyaya A. Ligand mobility regulates B cell receptor clustering and signaling activation. Biophys J. (2014) 106:26-36. doi: 10.1016/j.bpj.2013.10.043

41. Luxembourg AT, Brunmark A, Kong Y, Jackson MR, Peterson PA, Sprent J, et al. Requirements for stimulating naive CD8+ T cells via signal 1 alone. $J$ Immunol. (1998) 161:5226-35.

42. Dillard P, Varma R, Sengupta K, Limozin L. Ligand-mediated friction determines morphodynamics of spreading T cells. Biophys J. (2014) 107:262938. doi: 10.1016/j.bpj.2014.10.044

43. Guinamard R, Okigaki M, Schlessinger J, Ravetch JV. Absence of marginal zone B cells in Pyk-2-deficient mice defines their role in the humoral response. Nat Immunol. (2000) 1:31-6. doi: 10.1038/76882

44. Girkontaite I, Missy K, Sakk V, Harenberg A, Tedford K, Pötzel T, et al. Lsc is required for marginal zone $\mathrm{B}$ cells, regulation of lymphocyte motility and immune responses. Nat Immunol. (2001) 2:855-62. doi: 10.1038/ni0901-855

45. Hsu M-C, Toellner K-M, Vinuesa CG, Maclennan ICM. B cell clones that sustain long-term plasmablast growth in T-independent extrafollicular antibody responses. Proc Natl Acad Sci USA. (2006) 103:5905-10. doi: 10.1073/pnas.0601502103

46. Haas KM. Programmed cell death 1 suppresses b-1b cell expansion and longlived IgG production in response to T cell-independent type 2 antigens. $J$ Immunol. (2011) 187:5183-95. doi: 10.4049/jimmunol.1101990

47. Carrasco YR, Batista FD. B cells acquire particulate antigen in a macrophagerich area at the boundary between the follicle and the subcapsular sinus of the lymph node. Immunity. (2007) 27:160-71. doi: 10.1016/j.immuni.2007.06.007

48. Caro-Maldonado A, Wang R, Nichols AG, Kuraoka M, Milasta S, Sun LD, et al. Metabolic reprogramming is required for antibody production that is suppressed in anergic but exaggerated in chronically BAFF-exposed B cells. $J$ Immunol. (2014) 192:3626-36. doi: 10.4049/jimmunol.1302062

49. Akkaya M, Traba J, Roesler AS, Miozzo P, Akkaya B, Theall BP, et al. Second signals rescue B cells from activation-induced mitochondrial dysfunction and death. Nat Immunol. (2018) 19:871-84. doi: 10.1038/s41590-018-0156-5

50. Jellusova J. Cross-talk between signal transduction and metabolism in B cells. Immunol Lett. (2018) 201:1-13. doi: 10.1016/j.imlet.2018.11.003

51. Price MJ, Patterson DG, Scharer CD, Boss JM. Progressive upregulation of oxidative metabolism facilitates plasmablast differentiation to a T-independent antigen. Cell Rep. (2018) 23:3152-9. doi: 10.1016/j.celrep.2018.05.053

52. Boothby M, Rickert RC. Metabolic regulation of the immune humoral response. Immunity. (2017) 46:743-55. doi: 10.1016/j.immuni.2017.04.009

53. Minguet S, Dopfer EP, Pollmer C, Freudenberg MA, Galanos C, Reth M, et al. Enhanced B-cell activation mediated by TLR4 and BCR crosstalk. Eur J Immunol. (2008) 38:2475-87. doi: 10.1002/eji.200738094

54. Sindhava VJ, Oropallo MA, Moody K, Naradikian M, Higdon LE, Zhou L, et al. A TLR9-dependent checkpoint governs B cell responses to DNA-containing antigens. J Clin Invest. (2017) 127:1651-63. doi: 10.1172/ JCI89931 
55. Dye JR, Palvanov A, Guo B, Rothstein TL. B cell receptor cross-talk: exposure to lipopolysaccharide induces an alternate pathway for B cell receptor-induced ERK phosphorylation and NF-кB activation. J Immunol. (2007) 179:229-35. doi: 10.4049/jimmunol.179.1.229

56. Jabara HH, McDonald DR, Janssen E, Massaad MJ, Ramesh N, Borzutzky A, et al. DOCK8 functions as an adaptor that links TLR-MyD88 signaling to B cell activation. Nat Immunol. (2012) 13:612-20. doi: 10.1038/ni.2305

57. Otipoby KL, Waisman A, Derudder E, Srinivasan L, Franklin A, Rajewsky K. The B-cell antigen receptor integrates adaptive and innate immune signals. Proc Natl Acad Sci USA. (2015) 112:12145-50. doi: 10.1073/pnas.1516428112

58. Morbach H, Schickel JN, Cunningham-Rundles C, Conley ME, Reisli I, Franco JL, et al. CD19 controls Toll-like receptor 9 responses in human B cells. J Allergy Clin Immunol. (2016) 137:889-898.e6. doi: 10.1016/j.jaci.2015.08.040

59. Schweighoffer E, Nys J, Vanes L, Smithers N, Tybulewicz VLJ. TLR4 signals in B lymphocytes are transduced via the B cell antigen receptor and SYK. J Exp Med. (2017) 214:1269-80. doi: 10.1084/jem.20161117

60. Suthers AN, Sarantopoulos S. TLR7/TLR9- and B cell receptor-signaling crosstalk: promotion of potentially dangerous B cells. Front Immunol. (2017) 8:775. doi: 10.3389/fimmu.2017.00775

61. Londhe P, Yu PY, Ijiri Y, Ladner KJ, Fenger JM, London C, et al. Classical NF$\kappa \mathrm{B}$ metabolically reprograms sarcoma cells through regulation of hexokinase 2. Front Oncol. (2018) 8:104. doi: 10.3389/fonc.2018.00104

62. Papa S, Choy PM, Bubici C. The ERK and JNK pathways in the regulation of metabolic reprogramming. Oncogene. (2019) 38:2223-40. doi: $10.1038 / \mathrm{s} 41388-018-0582-8$
63. Caro P, Kishan AU, Norberg E, Stanley IA, Chapuy B, Ficarro SB, et al. Metabolic signatures uncover distinct targets in molecular subsets of diffuse large B cell lymphoma. Cancer Cell. (2012) 22:547-60. doi: 10.1016/j.ccr.2012.08.014

64. Ricci JE, Chiche J. Metabolic reprogramming of non-Hodgkin's B-cell lymphomas and potential therapeutic strategies. Front Oncol. (2018) 8:556. doi: $10.3389 /$ fonc. 2018.00556

65. Sarapulov AV, Petrov P, Hernández-Pérez S, Šuštar V, Kuokkanen E, Vainio $M$, et al. Missing-in-metastasis/metastasis suppressor 1 regulates B cell receptor signaling, B cell metabolic potential and $\mathrm{T}$ cellindependent immune responses. bioRxiv. (2019) 782276. doi: 10.1101/ 782276v2

Conflict of Interest: The authors declare that the research was conducted in the absence of any commercial or financial relationships that could be construed as a potential conflict of interest.

Copyright (C) 2020 Sarapulov, Petrov, Hernández-Pérez, Šuštar, Kuokkanen, Cords, Samuel, Vainio, Fritzsche, Carrasco and Mattila. This is an open-access article distributed under the terms of the Creative Commons Attribution License (CC BY). The use, distribution or reproduction in other forums is permitted, provided the original author(s) and the copyright owner(s) are credited and that the original publication in this journal is cited, in accordance with accepted academic practice. No use, distribution or reproduction is permitted which does not comply with these terms. 